Article

\title{
Ring Expansion of Alkylidenecarbenes Derived from Lactams, Lactones, and Thiolactones into Strained Heterocyclic Alkynes: A Theoretical Study
}

\author{
Nguyen Nhat Thu Le ${ }^{1}$, Josefine Just ${ }^{1}$, Jonathan M. Pankauski ${ }^{1}$, Paul R. Rablen ${ }^{2, *(1)}$ and \\ Dasan M. Thamattoor $1, *$ (D) \\ 1 Department of Chemistry, Colby College, Waterville, ME 04901, USA; nnle@colby.edu (N.N.T.L.); \\ jjust@colby.edu (J.J.); jmpank21@colby.edu (J.M.P.) \\ 2 Department of Chemistry and Biochemistry, Swarthmore College, 500 College Avenue, \\ Swarthmore, PA 19081, USA \\ * Correspondence: prablen1@swarthmore.edu (P.R.R.); dmthamat@colby.edu (D.M.T.); \\ Tel.: +1-207-859-5765 (D.M.T.)
}

Academic Editor: Igor V. Alabugin

Received: 30 December 2018; Accepted: 6 February 2019; Published: 7 February 2019

\begin{abstract}
Strained cycloalkynes are of considerable interest to theoreticians and experimentalists, and possess much synthetic value as well. Herein, a series of cyclic alkylidenecarbenes-formally obtained by replacing the carbonyl oxygen of four-, five-, and six-membered lactams, lactones, and thiolactones with a divalent carbon-were modeled at the CCSD(T)/cc-pVTZ/ / B3LYP/6-311+G F $^{* *}$ and $\operatorname{CCSD}(\mathrm{T}) / \mathrm{cc}-\mathrm{pVTZ} / / \mathrm{CCSD} / 6-311+\mathrm{G}^{* *}$ levels of theory. The singlet carbenes were found to be more stable than the triplets. The strained heterocyclic alkynes formed by ring expansion of these singlet carbenes were also modeled. Interestingly, the $C \equiv C$ bonds in the five-membered heterocycles, obtained from the rearrangement of $\beta$-lactam- and $\beta$-lactone-derived alkylidenecarbenes, displayed lengths intermediate between formal double and triple bonds. Furthermore, 2-(1-azacyclobutylidene)carbene was found to be nearly isoenergetic with its ring-expanded isomer, and 1-oxacyclopent-2-yne was notably higher in energy than its precursor carbene. In all other cases, the cycloalkynes were lower in energy than the corresponding carbenes. The transition states for ring-expansion were always lower for the 1,2-carbon shifts than for 1,2-nitrogen or oxygen shifts, but higher than for the 1,2-sulfur shifts. These predictions should be verifiable using carbenes bearing appropriate isotopic labels. Computed vibrational spectra for the carbenes, and their ring-expanded isomers, are presented and could be of value to matrix isolation experiments.
\end{abstract}

Keywords: alkylidenecarbenes; rearrangements; strained cycloalkynes; calculations

\section{Introduction}

Alkylidenecarbenes (1), and surrogate carbenoids (2), often undergo 1,2-shifts to furnish alkynes (3) by a process commonly referred to as the Fritsch-Buttenberg-Wiechell (FBW) rearrangement (Scheme 1a) [1-6]. By extending this method to cyclic alkylidenecarbenes (4) and carbenoids (5), in which the formally $\mathrm{sp}^{2}$-hybridized carbon connected to the carbene center is part of a ring, strained cycloalkynes (6) have also been generated (Scheme 1b) [4,7-9]. In recent years, our laboratory has reported that cyclopropanated phenanthrene systems such as 7 [10-13] and $8[14,15]$ can serve as photochemical precursors to 1 and 4 respectively (Scheme 2), and thus provide light-induced routes to the corresponding linear and cyclic alkynes. 
(a)

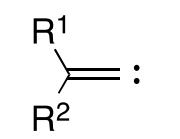

1

(b)

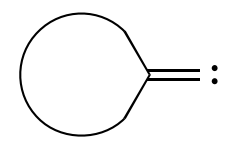

4

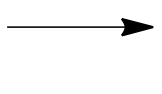

$\mathrm{R}^{1}=\mathrm{R}^{2}$

3

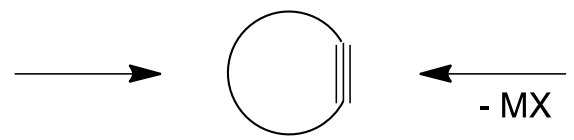

6<smiles>[X]C([R7])=C([R])[K]</smiles>

2

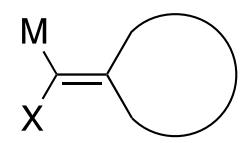

5

Scheme 1. (a) The ring expansion of alkylidene carbenes and carbenoids to linear alkynes. $R^{1}$ and $R^{2}$ may be the same or different. $\mathrm{M}$ is a metal and $\mathrm{X}$ a leaving group. (b) An analogous approach to the generation of cycloalkynes from cyclic alkylidenecarbenes and carbenoids.
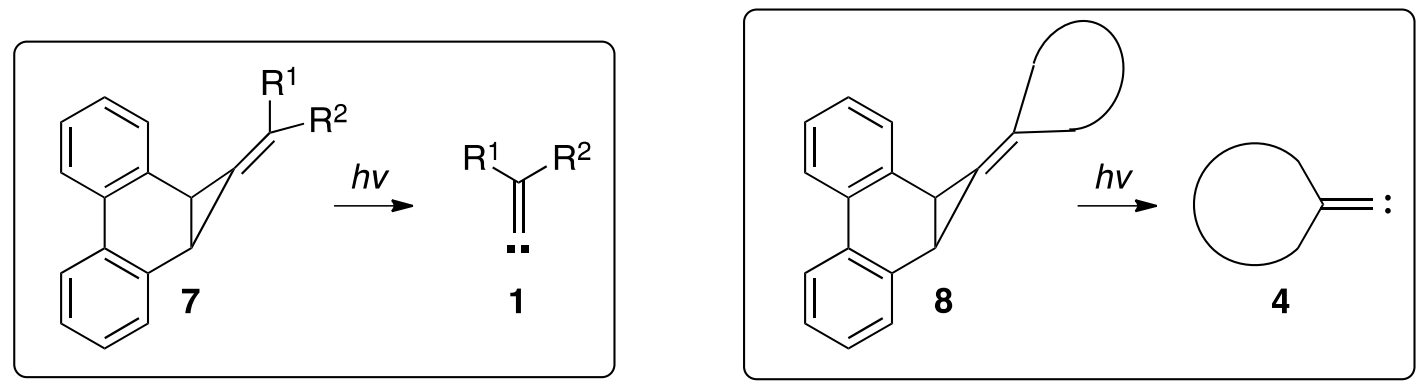

Scheme 2. Phenanthrene-based methylenecyclopropanes, exemplified by $\mathbf{7}$ and $\mathbf{8}$, can be used as photochemical sources of acyclic and cyclic alkylidenecarbenes respectively.

Strained cycloalkynes are no longer esoteric chemical curiosities of interest primarily to physical organic chemists and theoreticians [16-18]. In recent years, they have emerged as useful intermediates of substantial synthetic value [19-26]. Medium-sized, moderately strained carbocyclic and heterocyclic alkynes have proven to be of particular importance in the field of bioorthogonal chemistry [27-39]. Larger carbocyclic and oxygen incorporated enediynes have also been prepared, and their Bergman cyclization activity investigated for potential therapeutic use [40,41]. Herein, we describe our computational investigations into the chemistry of cyclic alkylidenecarbenes (10) derived by formally replacing the carbonyl oxygen of lactams, lactones, and thiolactones (9) with a divalent carbon (Scheme 3). The singlet-triplet energy gaps in these carbenes, and their ability to undergo ring expansion to the corresponding strained heterocyclic alkynes (11) have been investigated using density functional theory (B3LYP) [42-44] and coupled-cluster (CC) [45-47] methods. As the ring expansion could occur by a 1,2-shift of either the heteroatom or carbon, transition states for both pathways were computed and compared. Experiments with appropriate isotope labeling should be able to verify the predictions made below for the preferred rearrangement pathways. Vibrational spectra of the carbenes and the corresponding ring-expanded heterocyclic alkynes, which may be of potential value to matrix isolation experiments [48-50], are also presented.<smiles>[Y]C1CCCC1=O</smiles>

9<smiles>[X]C1CC2CCCC(C1)C2</smiles>

10

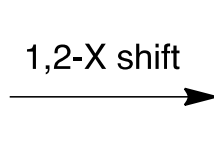

$\mathrm{n}=1,2$, or $3 ; \mathrm{X}=\mathrm{NH}, \mathrm{O}$, or $\mathrm{S}$

Scheme 3. The ring expansion of alkylidenecarbenes (10), derived from lactams, lactones, and thiolactones (9), into strained heterocyclic compounds (11). 


\section{Results and Discussion}

\subsection{Alkylidenecarbenes Derived from $\beta$-Lactam, $\beta$-Lactone, and $\beta$-Thiolactone}

The singlet-triplet energy gap $\left(\Delta \mathrm{E}_{\mathrm{S}-\mathrm{T}}\right)$ in the alkylidenecarbenes derived from $\beta$-lactam, $\beta$-lactone, and $\beta$-thiolactone were computed at the CCSD(T)/cc-pVTZ//B3LYP/6-311+G* and $\mathrm{CCSD}(\mathrm{T}) / \mathrm{cc}-\mathrm{pVTZ} / / \mathrm{CCSD} / 6-311+\mathrm{G}^{* *}$ levels of theory. In all calculations, the singlets were found to be significantly more stable than the triplets. This gap is consistent with the known preference of alkylidenecarbenes to adopt the singlet state, in which the lone pair can be nested in an approximately sp-hybridized orbital of the divalent carbon [6]. The PES for ring expansion of the singlet carbenes into the corresponding 1-X-cyclopent-2-ynes, which could occur by a 1,2-shift of either the heteroatom $X$ or carbon (Scheme 4), were also modeled. Results are discussed below.

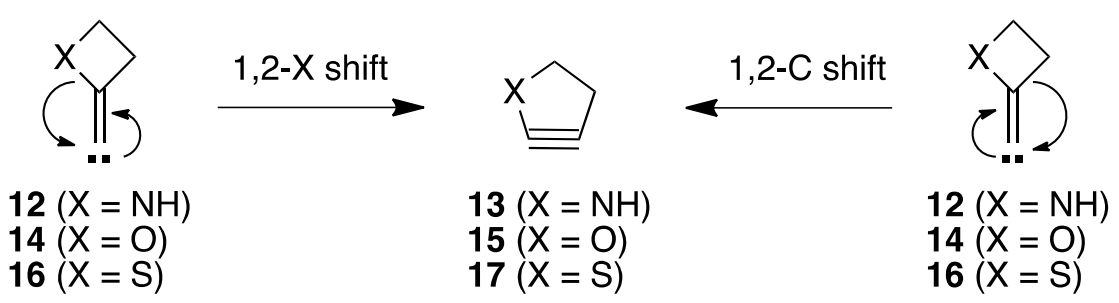

Scheme 4. Two pathways for the ring expansion of singlet alkylidenecarbenes derived from $\beta$-lactam, $\beta$-lactone, and $\beta$-thiolactone.

2.1.1. Ring Expansion of 2-(1-Azacyclobutylidene)carbene (12) into 1-Azacyclopent-2-yne (13)

The PES for ring expansion of singlet 12 into 1-aza-cyclopent-2-yne (13), which could occur by a 1,2-shift of either the nitrogen or carbon (Scheme 4), is depicted in Figure 1 using CCSD(T)/cc-pVTZ//CCSD/6-311+G ${ }^{* *}$ energies and structures. A similar diagram, based on CCSD(T)/cc-pVTZ//B3LYP/6-311+G** calculations, is provided in the Supplementary Materials (Figure S1).

As seen in Figure 1, singlet 12 is virtually isoenergetic with $\mathbf{1 3}$ and lies $18.6 \mathrm{kcal} / \mathrm{mol}$ below the triplet. Another distinctive feature of $\mathbf{1 3}$ is that its triple bond is significantly elongated with a calculated length of $1.28 \AA$. This value is intermediate between the length of a $\mathrm{C}=\mathrm{C}$ bond in cyclopentene $(\sim 1.32 \AA)$ [51] and our calculated value for the $C \equiv C$ bond (1.22 $\AA)$ in cyclopentyne [15]. Thus, 13 appears to display a partial triple bond, rather than a formal one, in order to alleviate ring strain. Furthermore, the conversion of singlet $\mathbf{1 2}$ into $\mathbf{1 3}$ appears to favor a 1,2-carbon shift, which has a significantly lower barrier than for a 1,2-nitrogen shift. This preference could stem from at least two factors. One is the "bystander effect" [52] of nitrogen that accelerates the 1,2-migration of carbon. In other words, as the carbon begins to shift, a decrease in electron density at the migration origin in the transition state, as evident from a Natural Population Analysis (NPA) [53,54] (see Supplementary Materials), could be stabilized by electron donation from the nitrogen. A second possible explanation is that the resonance contributions in $\mathbf{1 2}$ imparts a partial double bond character to the N-C ( $\left.\mathrm{sp}^{2}\right)$ bond (Figure 2) which would thus become even more resistant to cleavage. Importantly, such conjugation can be maintained during the 1,2-carbon shift. 


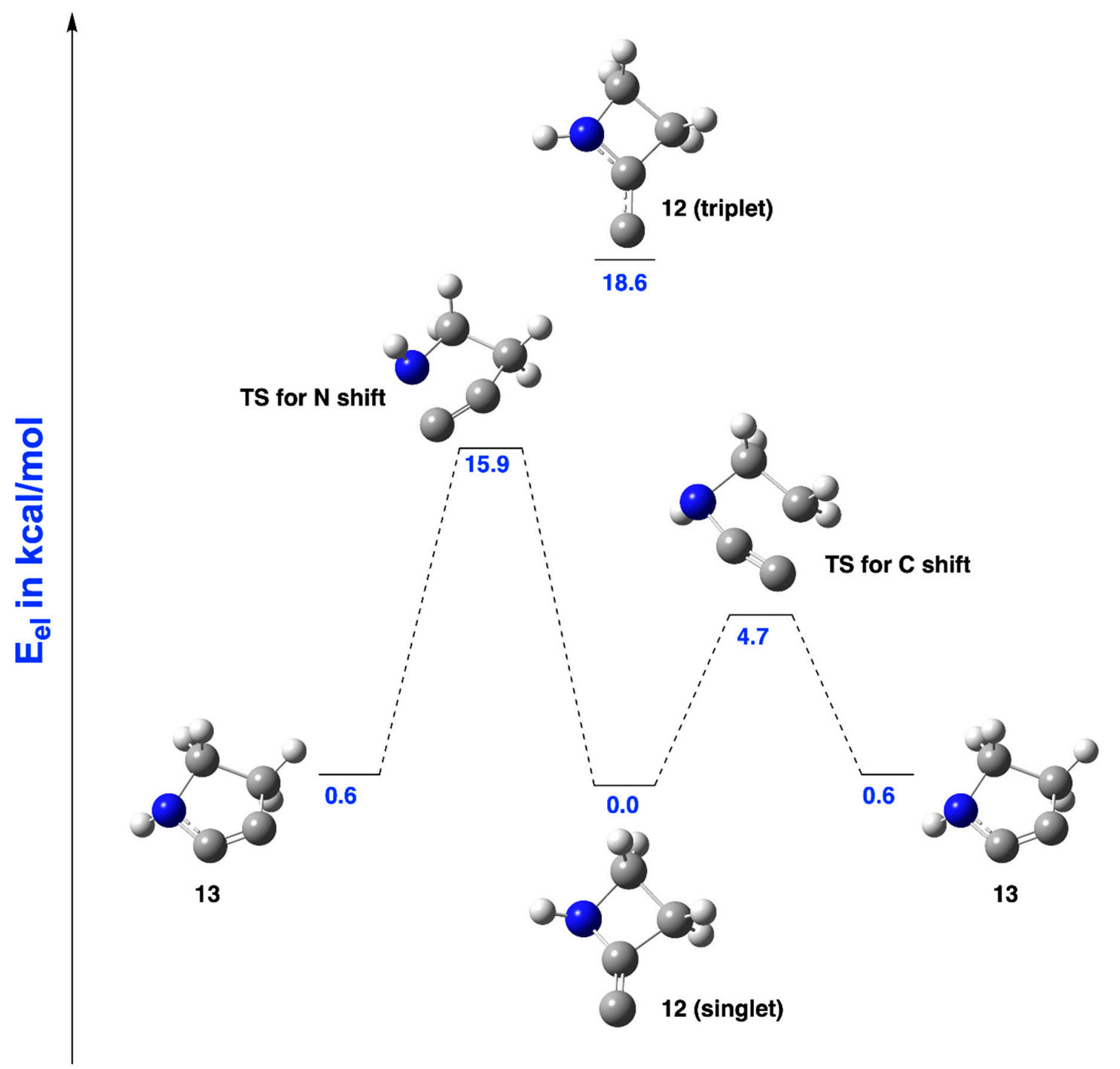

Figure 1. $\operatorname{CCSD}(\mathrm{T}) / \mathrm{cc}-\mathrm{pVTZ} / / \mathrm{CCSD} / 6-311+\mathrm{G}^{* *}$ structures and energies of singlet and triplet 12, and the PES for the conversion of singlet 12 into 1-azacyclopent-2-yne (13) by two different pathways.

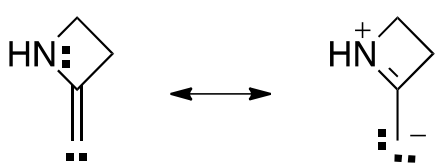

Figure 2. Resonance contributions in $\mathbf{1 2}$ showing a $\mathrm{C}=\mathrm{N}$ bond in the zwitterionic form.

Vibrational spectra of $\mathbf{1 2}$ and $\mathbf{1 3}$ computed at CCSD/6-311+G** are shown in Figure 3. The $\mathrm{C}=\mathrm{C}$ stretch in singlet 12 appears as a weak absorbance at $1711 \mathrm{~cm}^{-1}$. The two prominent bands at $763 \mathrm{~cm}^{-1}$ and $665 \mathrm{~cm}^{-1}$ are associated with the wagging motion of the $\mathrm{NH}$ bond coupled to ring oscillations. Triplet 12, on the other hand, shows a much stronger $C=C$ stretch at $1566 \mathrm{~cm}^{-1}$, and another strong absorbance at $447 \mathrm{~cm}^{-1}$ corresponding to the out of-plane wagging motions of the N-H bond and the methylene groups. The wagging of these two moieties in the plane of the ring is observed at $1175 \mathrm{~cm}^{-1}$. The spectrum of 13 shows a strong absorption at $1656 \mathrm{~cm}^{-1}$ associated with the stretching of the $\mathrm{NC} \equiv \mathrm{C}$ moiety. The wagging vibrations of the $\mathrm{NH}$ and methylene groups, in a direction perpendicular to the plane of the ring also show a strong absorbance at $716 \mathrm{~cm}^{-1}$. 


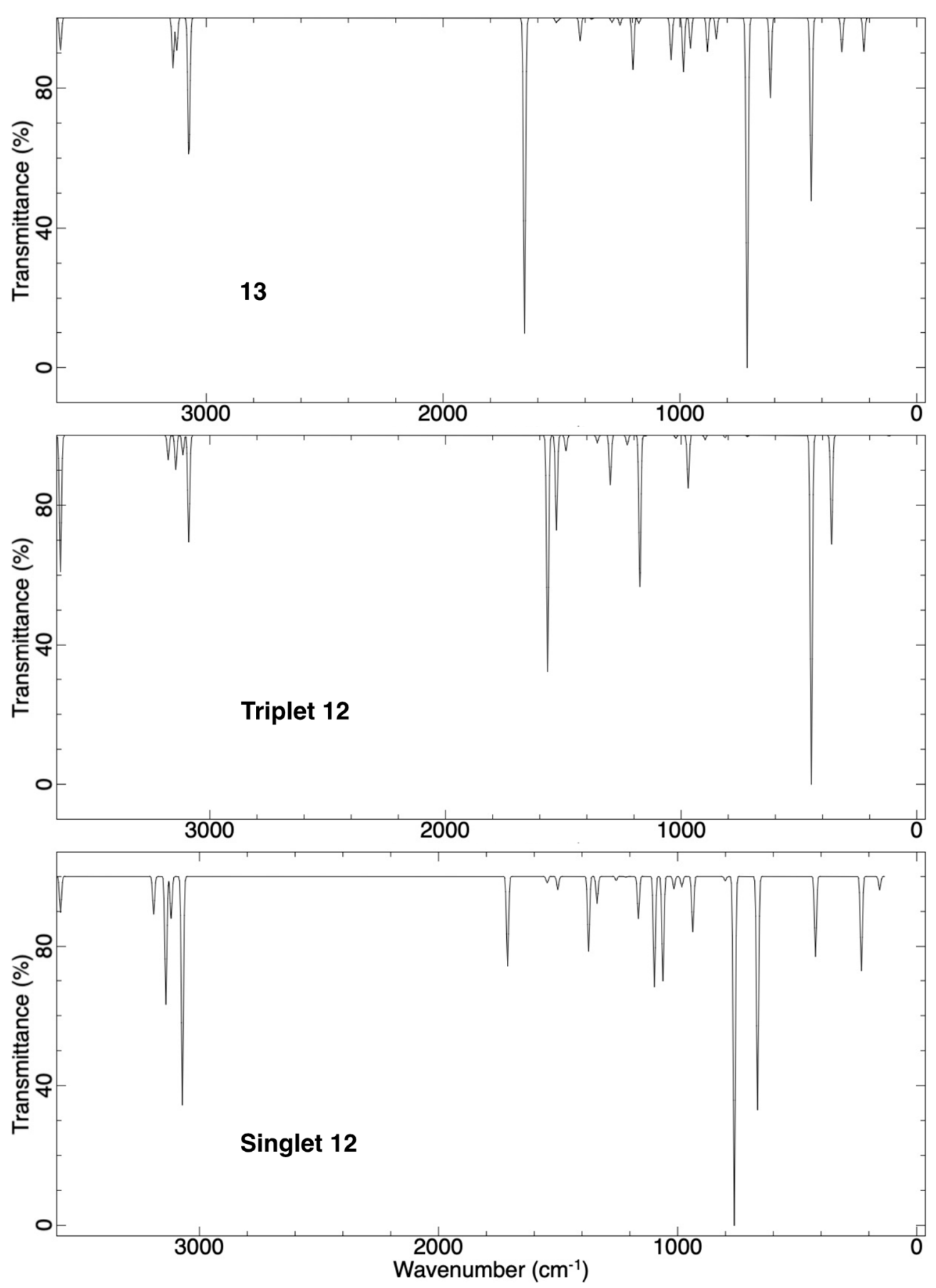

Figure 3. Vibrational spectra computed at CCSD/6-311+G** for singlet 12 (bottom), triplet 12 (middle), and 13 (top).

2.1.2. Ring Expansion of 2-(1-Oxacyclobutylidene)carbene (14) into 1-Oxacyclopent-2-yne (15)

Singlet 14 was found to lie $21.1 \mathrm{kcal} / \mathrm{mol}$ below the triplet according to CCSD(T)/cc-pVTZ//B3LYP/6-311+G** calculations (Supplementary Materials, Figure S2). The cycloalkyne 15, however, was found to be not a minimum at the DFT level of theory, instead reverting without barrier to 14. On the other hand, singlet and triplet 14, as well as 15, were all found to be minima on the CCSD/6-311+G** PES. Their structures and CCSD(T)/cc-pVTZ//CCSD/6-311+G** energies, along with the transition states for converting singlet $\mathbf{1 4}$ into $\mathbf{1 5}$ are depicted in Figure 4. Notably, 15 was found to be $5.6 \mathrm{kcal} / \mathrm{mol}$ higher in energy than singlet 14, and features a partial triple 
bond ( 1.26 $\AA$ ) much like 12. Similar to observations with the 12 to 13 rearrangement, the 1,2-carbon shift in singlet $\mathbf{1 4}$ is considerably more facile than the 1,2-oxygen shift. Thus, the reactivity of $\mathbf{1 4}$ appears to mirror that of $\mathbf{1 2}$, for the same reasons as those discussed above.

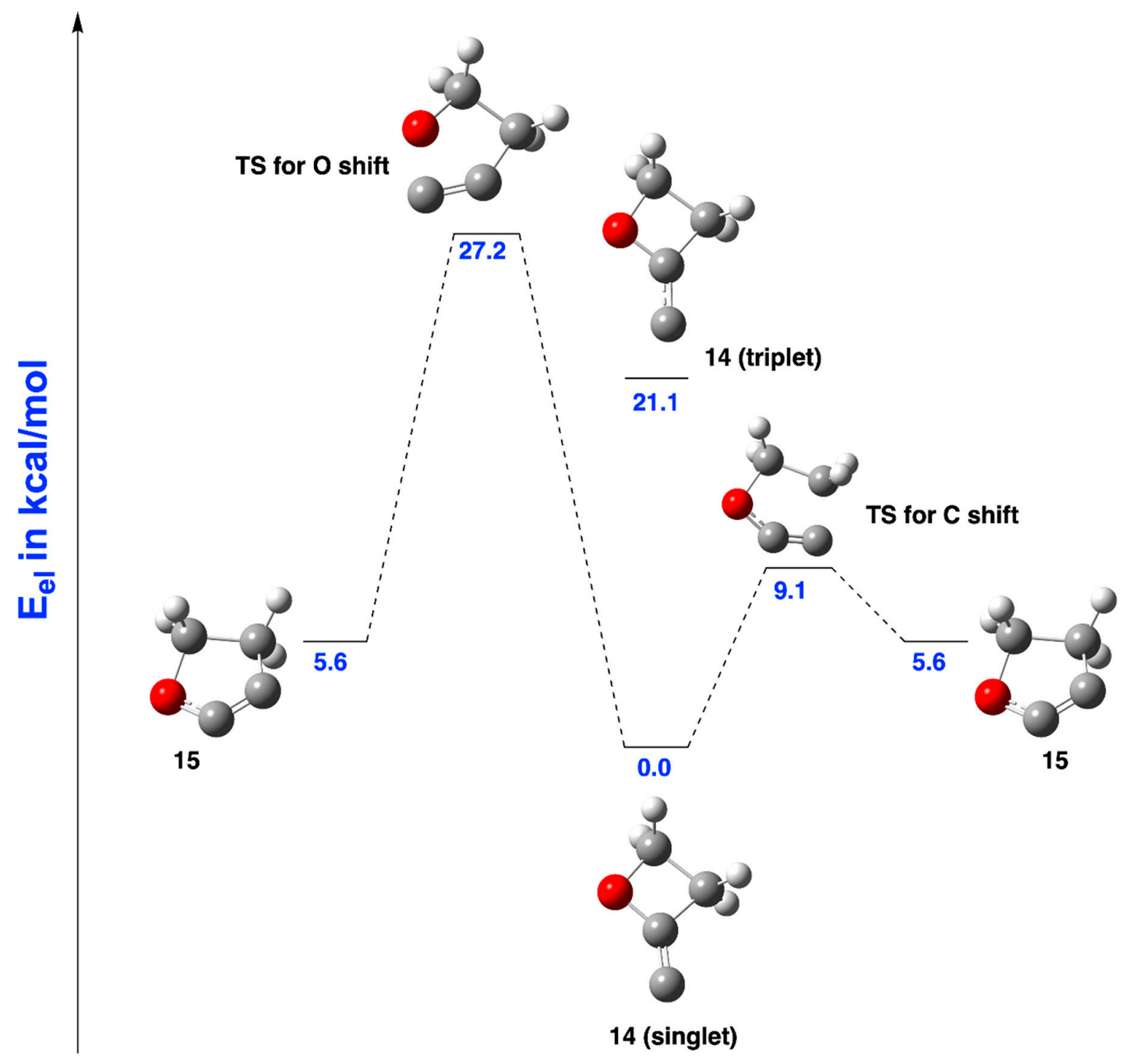

Figure 4. $\operatorname{CCSD}(\mathrm{T}) / \mathrm{cc}-\mathrm{pVTZ} / / \mathrm{CCSD} / 6-311+\mathrm{G}^{* *}$ structures and energies of singlet and triplet 13, and the PES for the conversion of singlet 14 into 1-oxacyclopent-2-yne (15) by two different pathways.

Vibrational spectra of $\mathbf{1 4}$ and $\mathbf{1 5}$ computed at CCSD/6-311+G** are shown in Figure 5. In the spectrum of singlet 14, an especially strong absorbance was found at $1102 \mathrm{~cm}^{-1}$, which corresponds to the in-plane, side-to-side motion of the endocyclic sp $^{2}$-hybridized carbon. A similar motion was also observed for triplet $\mathbf{1 4}$, with a strong absorbance at $1138 \mathrm{~cm}^{-1}$. The spectrum of triplet 14 also displays another moderately strong absorbance at $970 \mathrm{~cm}^{-1}$ corresponding to the in-plane oscillation of the oxygen. Conspicuously, only very weak absorbances were found for $\mathrm{C}=\mathrm{C}$ stretch in both singlet and triplet 14. The spectrum of 15 shows strong bands at $1803 \mathrm{~cm}^{-1}$ and $453 \mathrm{~cm}^{-1}$ associated with vibrations of the $\mathrm{OC} \equiv \mathrm{C}$ moiety, and a moderate absorbance at $1153 \mathrm{~cm}^{-1}$ corresponding to the in-plane stretching of the OC(sp)bond. 

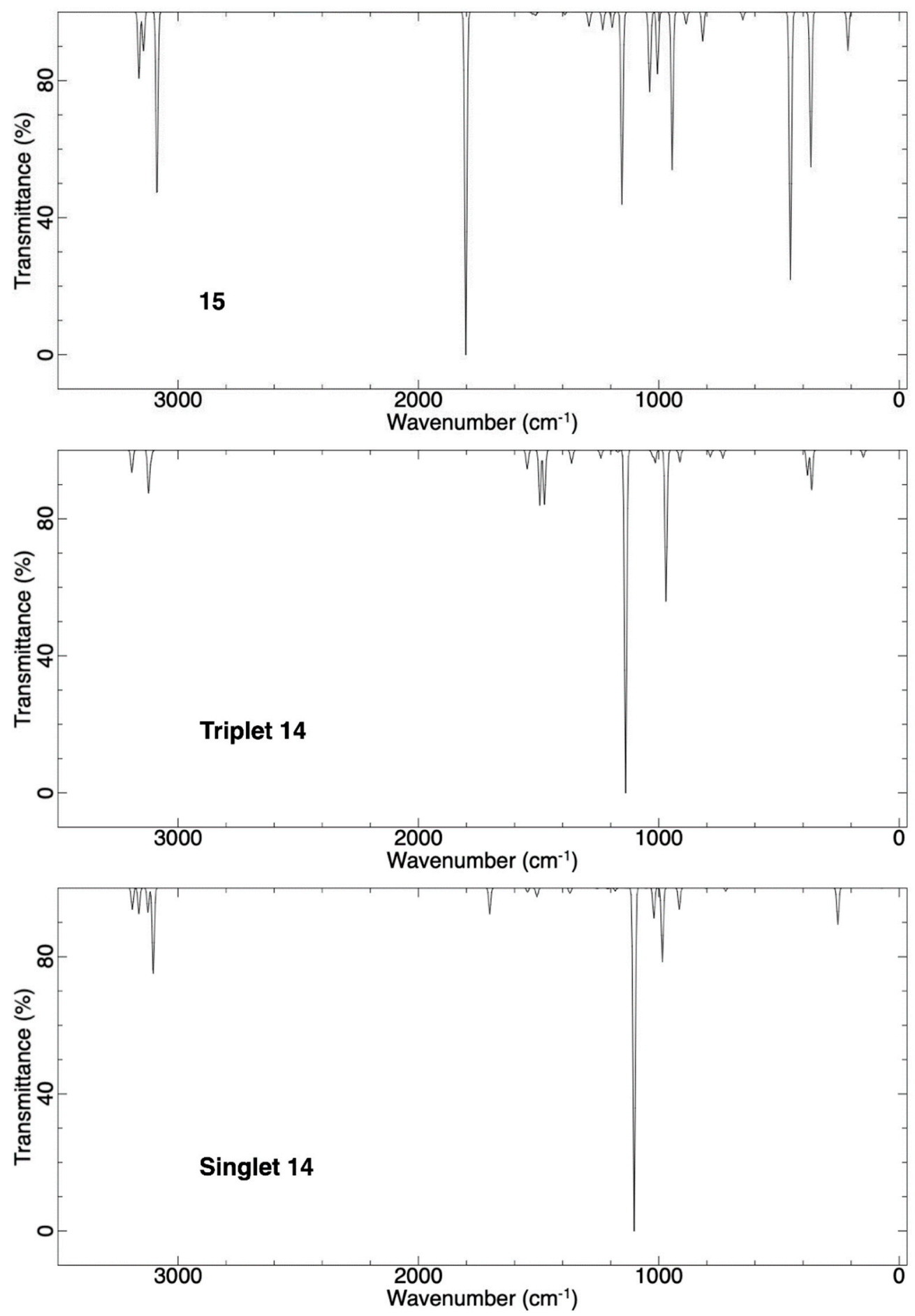

Figure 5. Vibrational spectra computed at CCSD/6-311+G** for singlet 14 (bottom), triplet 14 (middle), and 15 (top).

2.1.3. Ring Expansion of 2-(1-Thiocyclobutylidene)carbene (16) into 1-Thiocyclopent-2-yne (17)

Given the larger size of sulfur, and the attendant incorporation of longer bonds in the ring, one might expect that the thio carbene 16 and 1-thiocyclopent-2-yne (17) might behave somewhat differently than the aza and oxa analogs discussed above. These expectations are indeed borne out by $\operatorname{CCSD}(\mathrm{T}) / \mathrm{cc}-\mathrm{pVTZ} / / \mathrm{CCSD} / 6-311+\mathrm{G}^{* *}$ calculations (Figure 6). As with $\mathbf{1 2}$ and 14, singlet $\mathbf{1 6}$ is more stable than the triplet $\left(\Delta \mathrm{E}_{\mathrm{S}-\mathrm{T}}=-28.7 \mathrm{kcal} / \mathrm{mol}\right)$. The PES for the conversion of singlet 16 into 17, however, does show some important differences compared to the profiles seen in Figures 1 and 4. For 
one, the carbon-carbon triple bond $\mathbf{1 6}$ is shorter ( 1.24 $\AA$ ) than in either $\mathbf{1 2}$ or $\mathbf{1 4}$. Furthermore, $\mathbf{1 6}$ is lower in energy than singlet 15 by $-7.2 \mathrm{kcal} / \mathrm{mol}$. This could be attributed to lesser ring strain in 16 compared to 12 and 14, a benefit accorded by the incorporation of longer carbon-sulfur bonds in the ring. A second important difference is that the ring expansion of $\mathbf{1 6}$ to $\mathbf{1 7}$ prefers to occur by a 1,2-sulfur shift, which is almost barrier-free, compared to a 1,2-carbon shift that needs an activation energy of almost $10 \mathrm{kcal} / \mathrm{mol}$. This behavior may be attributed to the greater nucleophilicity and size of sulfur. The $3 p$ orbital on sulfur is less effective for resonance stabilization due to poor overlap with the $2 p$ orbital on the adjacent carbon. On the other hand, a lone pair on the larger sulfur atom can interact with the empty orbital on the carbenic center to initiate bonding at a longer distance than possible with either nitrogen or oxygen. A similar profile, obtained at the CCSD(T)/cc-pVTZ/ / B3LYP/6-311+ $\mathrm{G}^{* *}$ level of theory, is provided in the Supplementary Materials (Figure S3).

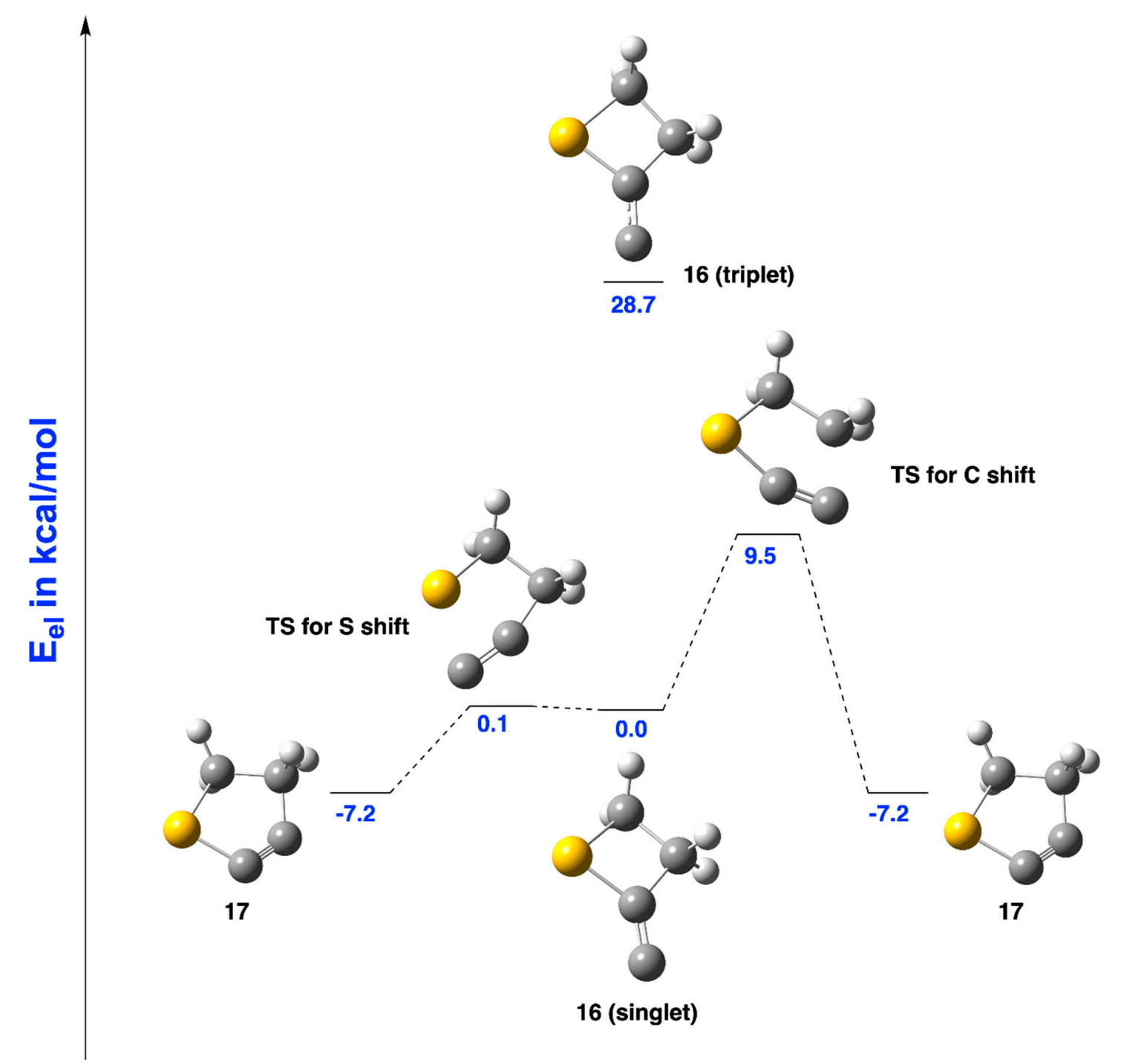

Figure 6. $\operatorname{CCSD}(\mathrm{T}) / \mathrm{cc}-\mathrm{pVTZ} / / \mathrm{CCSD} / 6-311+\mathrm{G}^{* *}$ structures and energies of singlet and triplet 15, and the PES for the conversion of singlet 16 into 1-thiocyclopent-2-yne (17) by two different pathways.

Vibrational spectra of $\mathbf{1 6}$ and $\mathbf{1 7}$ computed at CCSD/6-311+G** are shown in Figure 7. The IR spectrum of singlet 16 is relatively clean and shows a strong absorbance at $1686 \mathrm{~cm}^{-1}$ for the $C=C$ stretch. The spectrum of triplet 16 shows a moderately strong absorbance at $1265 \mathrm{~cm}^{-1}$ for the wagging motions of the two methylene groups in the ring. The stretching vibrations of the bond between $\mathrm{O}$ and the endocyclic sp $\mathrm{s}^{2}$ carbon have an absorbance at $691 \mathrm{~cm}^{-1}$, and another absorbance at $997 \mathrm{~cm}^{-1}$ 
is seen for the stretching vibrations of the bond between the $\mathrm{CH}_{2}$ group and the double bond. The alkynyl group in $\mathbf{1 7}$ shows two distinct bands in the IR spectrum, a weak absorbance at $1970 \mathrm{~cm}^{-1}$ for its stretching vibrations and a strong absorbance at $353 \mathrm{~cm}^{-1}$ for its wagging motions in the plane of the ring. Absorbances due to $\mathrm{C}-\mathrm{H}$ stretches are seen $3080 \mathrm{~cm}^{-1}$, and the stretching motion of the bond between $\mathrm{O}$ and the alkynyl group absorbs at $784 \mathrm{~cm}^{-1}$.
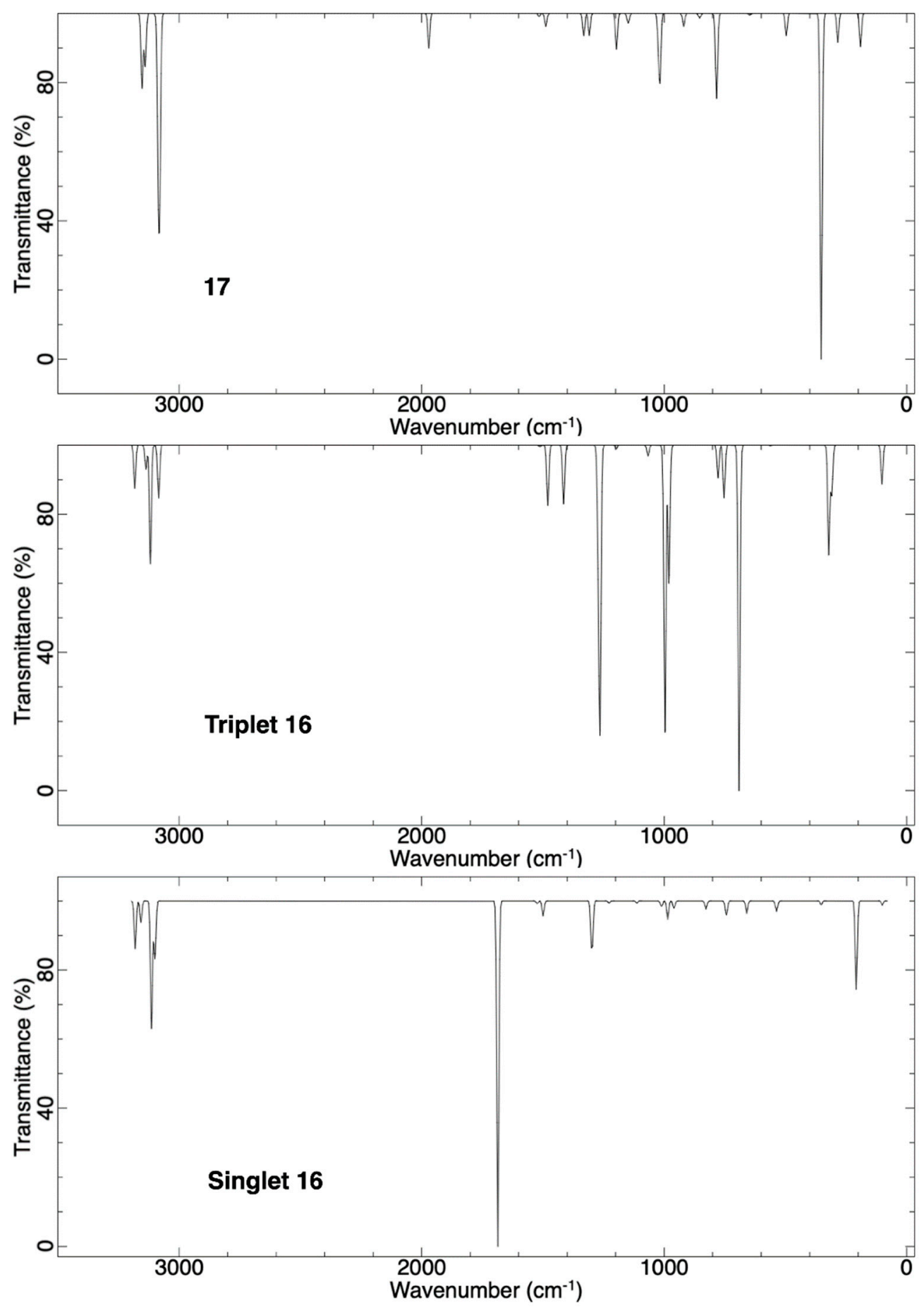

Figure 7. Vibrational spectra computed at CCSD/6-311+G* for singlet $\mathbf{1 6}$ (bottom), triplet $\mathbf{1 6}$ (middle), and 17 (top). 


\subsection{Alkylidenecarbenes Derived from $\gamma$-Lactam, $\gamma$-Lactone, and $\gamma$-Thiolactone}

The $\Delta \mathrm{E}_{\mathrm{S}-\mathrm{T}}$ gaps of the the alkylidenecarbenes in this series also favor the singlets at the $\operatorname{CCSD}(\mathrm{T}) / \mathrm{cc}-\mathrm{pVTZ} / / \mathrm{B} 3 \mathrm{LYP} / 6-311+\mathrm{G}^{* *}$ and CCSD(T)/cc-pVTZ/ /CCSD/6-311+G** levels of theory. Structures and energies of these carbenes, and the PES for conversion of the singlet carbenes into corresponding 1-X-cyclohex-2-ynes, by a 1,2-shift of X or carbon (Scheme 5), are described below.

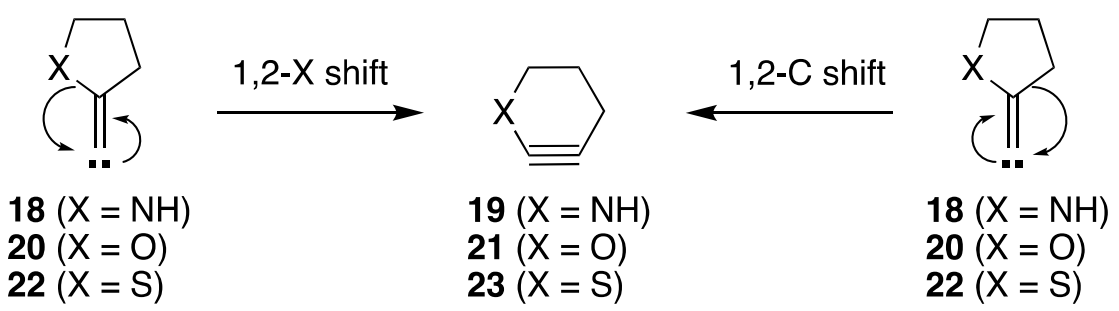

Scheme 5. Ring expansion of singlet alkylidenecarbenes, derived from $\gamma$-lactam, $\gamma$-lactone, and $\gamma$-thiolactone, by a 1,2 shift of either $\mathrm{X}$ or carbon.

2.2.1. Ring Expansion of 2-(1-Azacyclopentylidene)carbene (18) into 1-Azacyclohex-2-yne (19)

As depicted in Figure 8, CCSD(T)/cc-pVTZ//CCSD/6-311+G* calculations show that singlet 18 is about $18.7 \mathrm{kcal} / \mathrm{mol}$ lower in energy than the triplet. Furthermore, in sharp contrast to what has been described above with 12 and 13, the cyclic alkyne 19 is lower in energy than singlet 18 by $10.0 \mathrm{kcal} / \mathrm{mol}$. This result is understandable given that 19 , which features a six-membered ring, is much less strained than the five-membered ring in 13. The conversion of singlet 18 into 19 preferentially occurs by a 1,2-carbon shift, which needs to overcome a barrier of $8.3 \mathrm{kcal} / \mathrm{mol}$. A 1,2-nitrogen shift, on the other hand, has a much higher activation energy of $20.5 \mathrm{kcal} / \mathrm{mol}$. A similar profile, obtained by CCSD(T)/cc-pVTZ/ / B3LYP / 6-311+G** calculations, is provided in the (Figure S4).
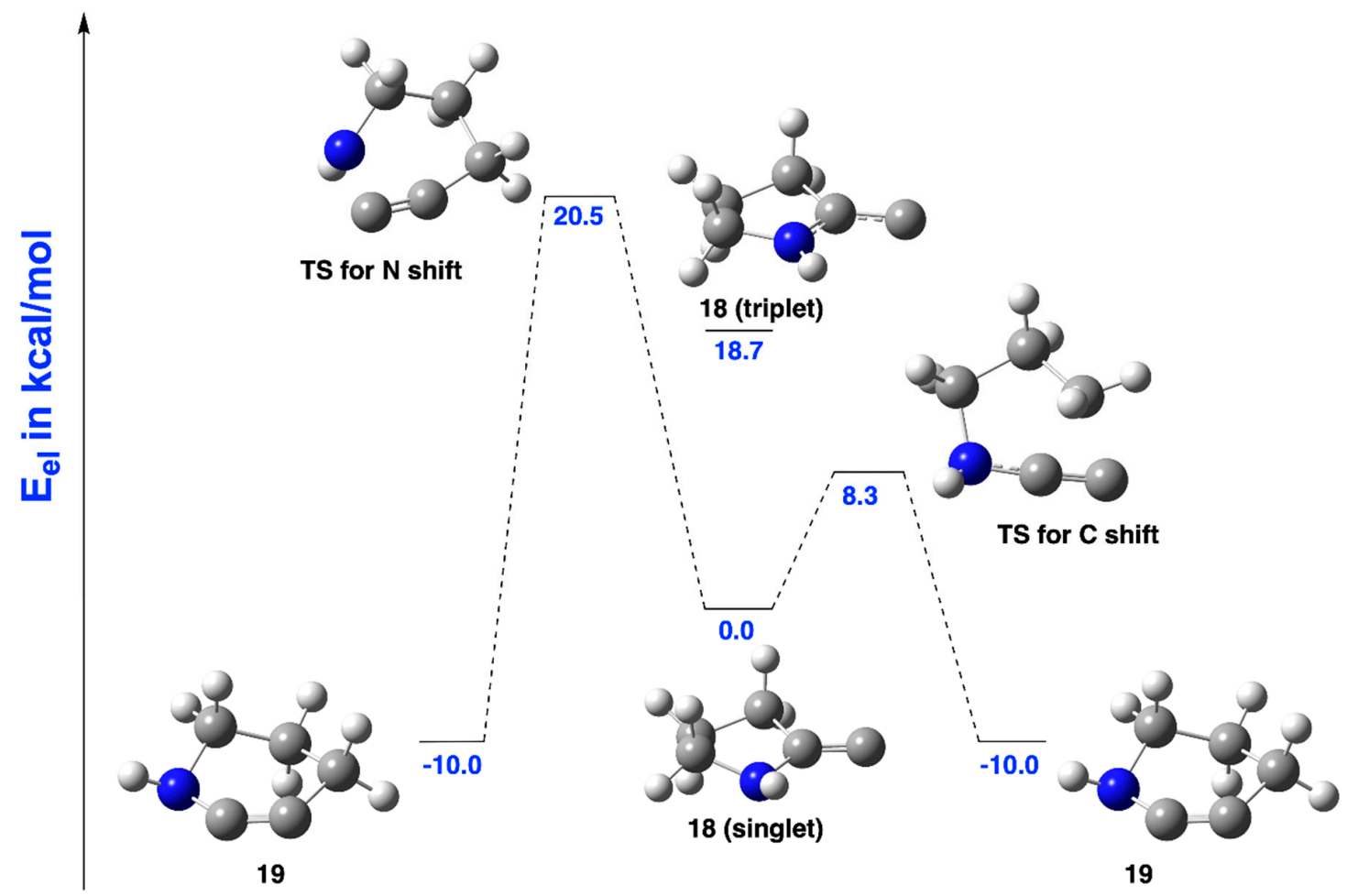

Figure 8. $\operatorname{CCSD}(\mathrm{T}) / \mathrm{cc}-\mathrm{pVTZ} / / \mathrm{CCSD} / 6-311+\mathrm{G}^{* *}$ structures and energies of singlet and triplet 18, and the PES for the conversion of singlet 18 into 1-azacyclohex-2-yne (19) by two different pathways. 
CCSD/6-311+G** calculated vibrational spectra of singlet and triplet $\mathbf{1 8}$, as well as $\mathbf{1 9}$, are shown in Figure 9. The spectrum of singlet 18 shows strong absorbances at $1167 \mathrm{~cm}^{-1}$, for the in-plane motion of the endocyclic sp $\mathrm{s}^{2}$ carbon, and $531 \mathrm{~cm}^{-1}$ for the out of plane $\mathrm{N}-\mathrm{H}$ bend. The $\mathrm{C}=\mathrm{C}$ stretch in singlet 18 appears at a frequency of $1706 \mathrm{~cm}^{-1}$. Triplet 18 shows a band at $1568 \mathrm{~cm}^{-1}$, for the vibrations of the $\mathrm{C}=\mathrm{C}-\mathrm{N}$ moiety, and another strong absorbance at $566 \mathrm{~cm}^{-1}$ for the out-of-plane wagging of the N-H bond. The spectrum of 19 shows the familiar stretching frequency of the alkynyl group at $2137 \mathrm{~cm}^{-1}$ and strong absorbances at $903 \mathrm{~cm}^{-1}$ and $782 \mathrm{~cm}^{-1}$ for the wagging motions of the N-H bond coupled to the vibrations of the methylene groups.
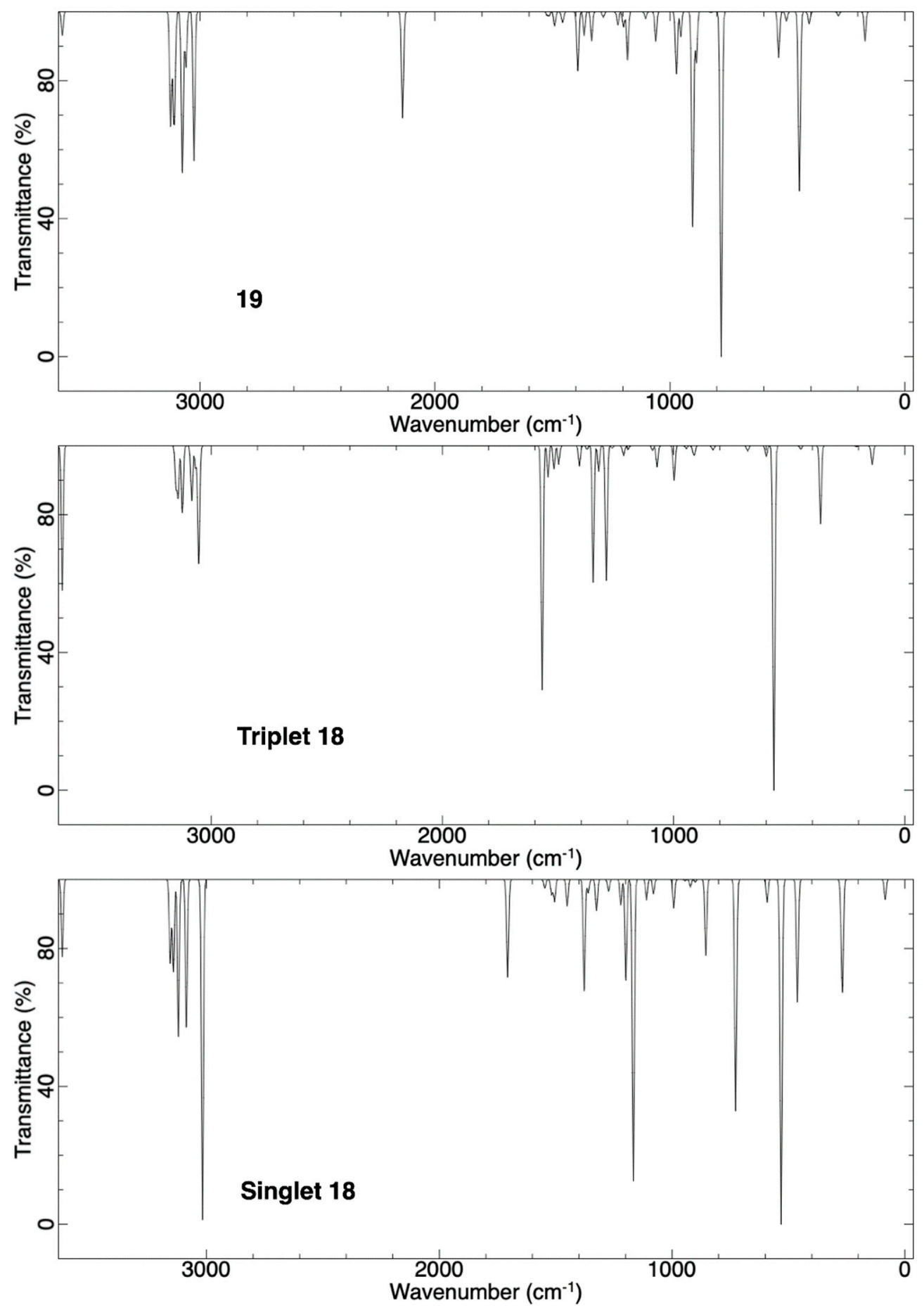

Figure 9. Vibrational spectra computed at CCSD/6-311+ $\mathrm{G}^{* *}$ for singlet $\mathbf{1 8}$ (bottom), triplet $\mathbf{1 8}$ (middle), and 19 (top). 
2.2.2. Ring Expansion of 2-(1-Oxacyclopentylidene)carbene (20) into 1-Oxacyclohex-2-yne (21)

Singlet 20 was found to be $24.9 \mathrm{kcal} / \mathrm{mol}$ below the triplet, and $6.3 \mathrm{kcal} / \mathrm{mol}$ above cycloalkyne 21, according to CCSD(T)/cc-pVTZ//CCSD/6-311+G** (Figure 10). These calculations also reveal that the barrier for converting singlet 20 into 21 by a 1,2-carbon shift is $10.1 \mathrm{kcal} / \mathrm{mol}$, whereas the transition state for accomplishing the ring expansion by a 1,2-oxygen shift is much higher at $28.8 \mathrm{kcal} / \mathrm{mol}$. These results are also summarized in Figure 10. Structures and energies from the $\operatorname{CCSD}(\mathrm{T}) / \mathrm{cc}-\mathrm{pVTZ} / / \mathrm{B} 3 \mathrm{LYP} / 6-311+\mathrm{G}^{* *}$ calculations on this system are provided in the Supplementary Materials (Figure S5).

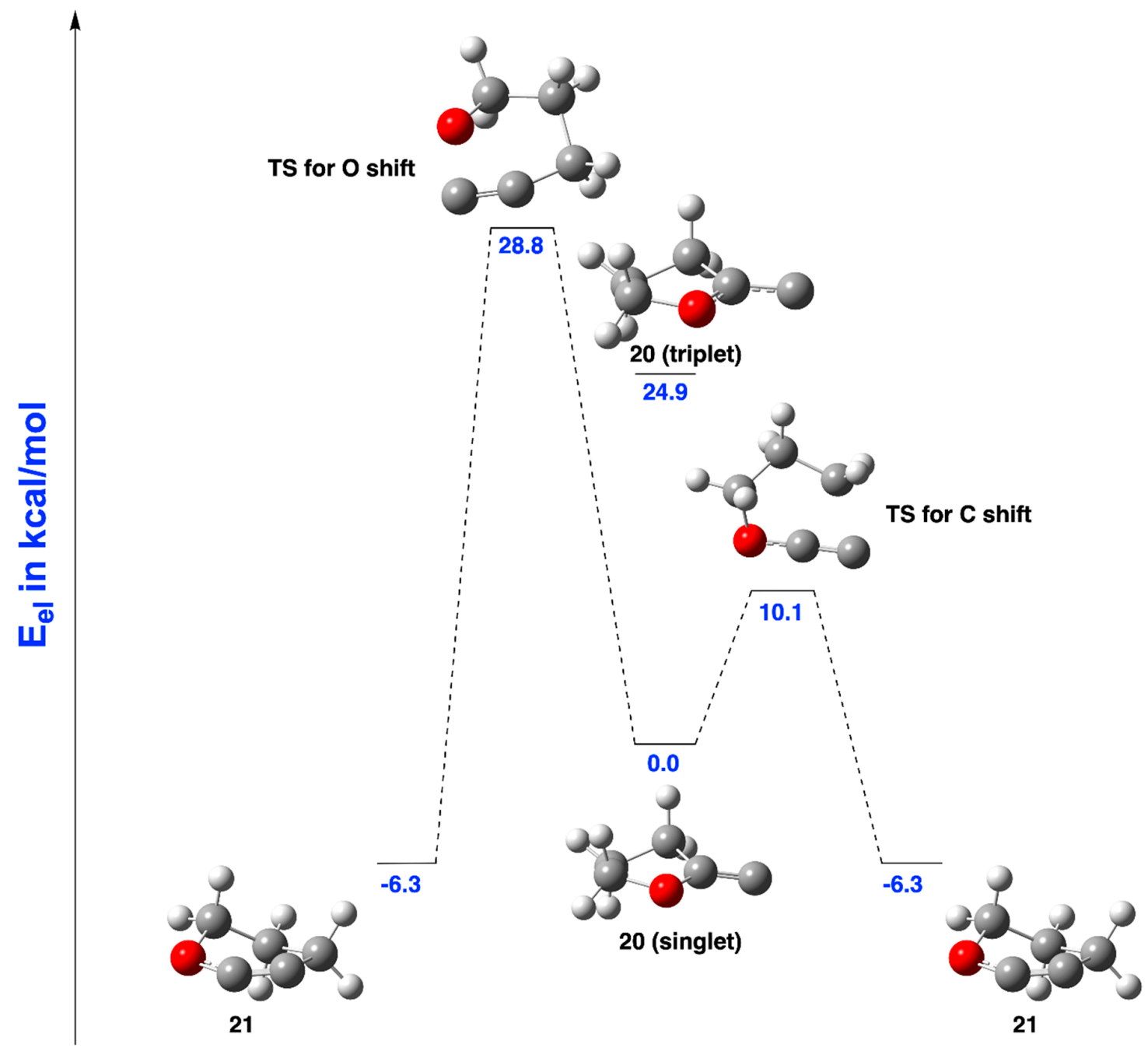

Figure 10. $\operatorname{CCSD}(\mathrm{T}) / \mathrm{cc}-\mathrm{pVTZ} / / \mathrm{CCSD} / 6-311+\mathrm{G}^{* *}$ structures and energies of singlet and triplet 20, and the PES for the conversion of singlet 20 into 1-oxacyclohex-2-yne (21) by two different pathways.

The computed vibrational spectra $\left(\mathrm{CCSD} / 6-311+\mathrm{G}^{* *}\right)$ of 20 (singlet and triplet) and 21 are displayed in Figure 11. The strongest absorbances in the spectrum of singlet and triplet 20 appear at $1157 \mathrm{~cm}^{-1}$ and $1236 \mathrm{~cm}^{-1}$ respectively and correspond to the stretching vibration of the bond between oxygen and the endocyclic sp $\mathrm{p}^{2}$ carbon. The spectrum of 21 shows a strong absorbance at $2132 \mathrm{~cm}^{-1}$ characteristic of the alkynyl group. Stretching vibrations of the bond between oxygen and the alkyne moiety absorb at $1178 \mathrm{~cm}^{-1}$, and the in-plane motions of the $\mathrm{OC} \equiv \mathrm{C}$ group absorb at $407 \mathrm{~cm}^{-1}$. 

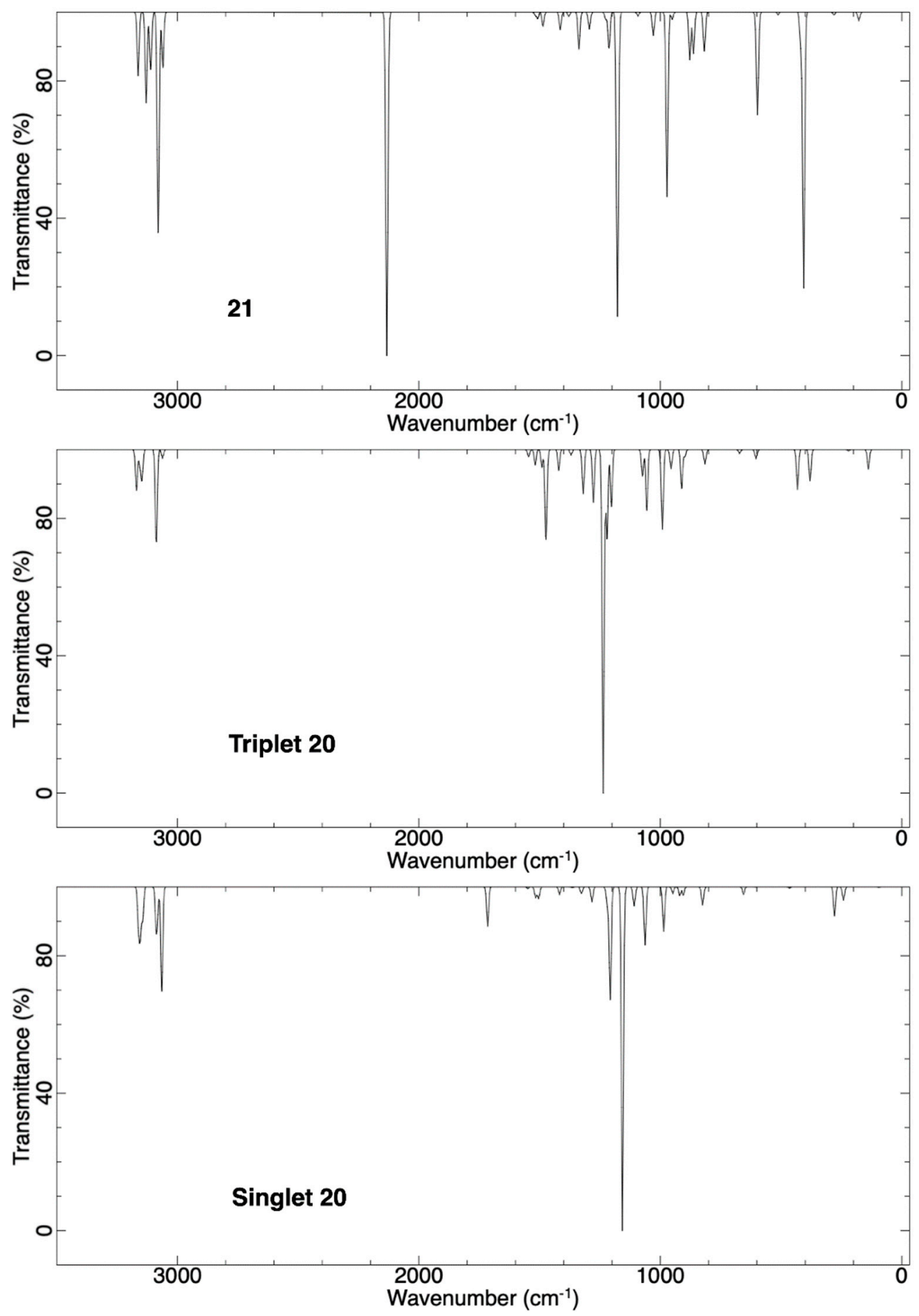

Figure 11. Vibrational spectra computed at CCSD/6-311+G** for singlet 20 (bottom), triplet 20 (middle), and 21 (top).

2.2.3. Ring Expansion of 2-(1-Thiacyclopentylidene)carbene (22) into 1-Thiacyclohex-2-yne (23)

According to CCSD(T)/cc-pVTZ//CCSD/6-311+G** calculations, singlet 22 lies $31.8 \mathrm{kcal} / \mathrm{mol}$ below the triplet, and $16.9 \mathrm{kcal} / \mathrm{mol}$ above thiocycloakyne 23 (Figure 12). The PES for conversion of singlet 22 into 23 is also shown in Figure 12 at this level of theory. Unlike the aza- and oxa-substituted analogs, and consistent with previous observations in the case of 16, carbene 22 prefers to form 23 by shifting the heteroatom. The 1,2-sulfur shift, which has a barrier of only $3.7 \mathrm{kcal} / \mathrm{mol}$, requires much less energy than a 1,2-carbon shift (barrier of $14.2 \mathrm{kcal} / \mathrm{mol}$ ) to form 23 . Similar results were obtained 
with CCSD(T)/cc-pVTZ//B3LYP/6-311+ $\mathrm{G}^{* *}$ calculations and are provided in the Supplementary Materials (Figure S6).

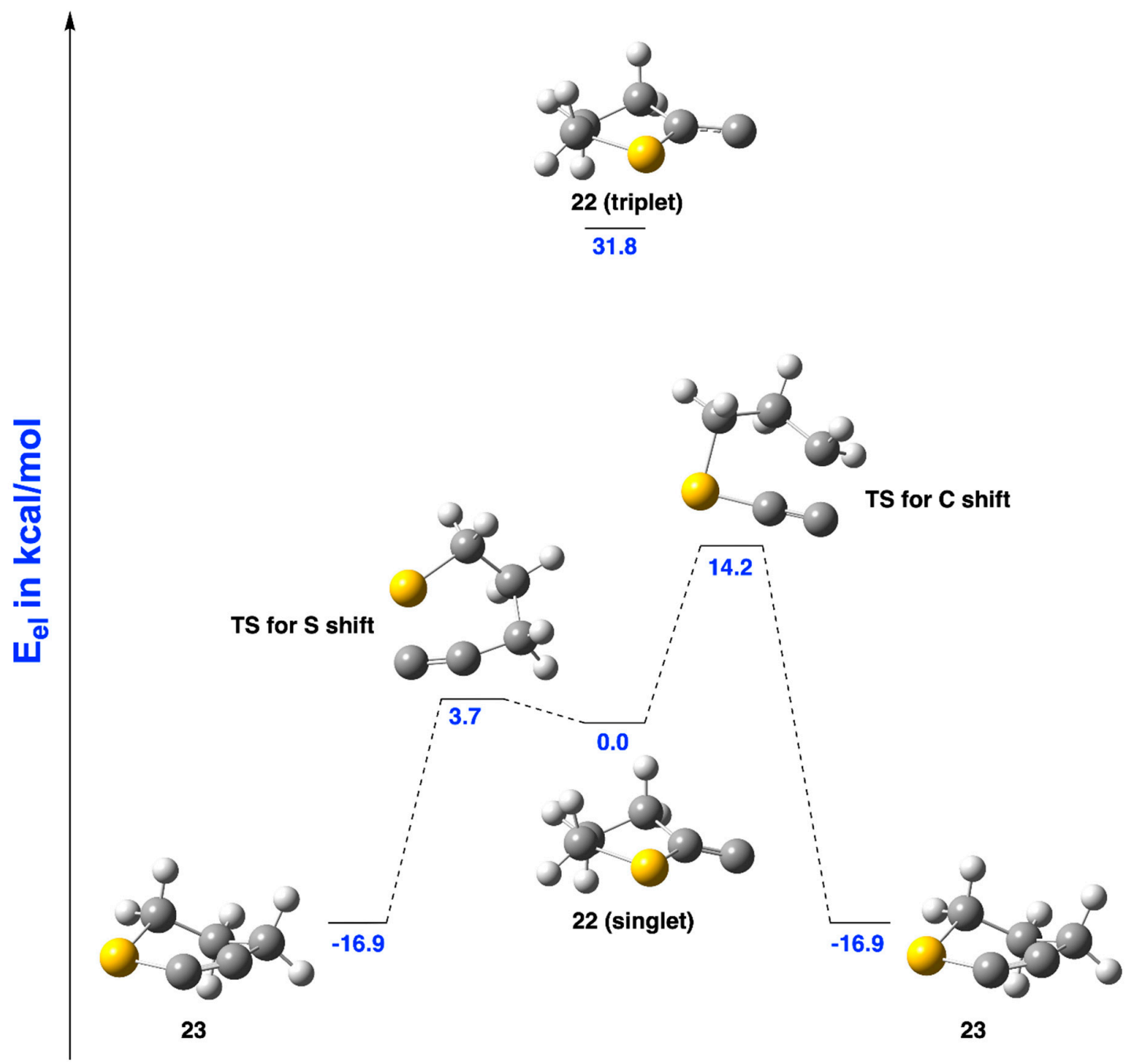

Figure 12. $\operatorname{CCSD}(\mathrm{T}) / \mathrm{cc}-\mathrm{pVTZ} / / \mathrm{CCSD} / 6-311+\mathrm{G}^{* *}$ structures and energies of singlet and triplet 22, and the PES for the conversion of singlet 22 into 1-thiocyclohex-2-yne (23) by two different pathways.

Vibrational spectra of 22 and 23 computed at CCSD/6-311+G** are shown in Figure 13. Singlet 22 shows a particularly strong absorbance at $1688 \mathrm{~cm}^{-1}$ for the $C=C$ stretch. Triplet 22 shows a moderate absorbance at $1389 \mathrm{~cm}^{-1}$ due to the $\mathrm{C}=\mathrm{C}$ stretch, whereas the stretching vibration of the bond between $\mathrm{S}$ and the sp $\mathrm{sp}^{2}$ carbon shows somewhat stronger absorbances at $1082 \mathrm{~cm}^{-1}$ and $681 \mathrm{~cm}^{-1}$. The $\mathrm{C} \equiv \mathrm{C}$ stretching frequency for 23 appears at $2134 \mathrm{~cm}^{-1}$ but is rather weak compared to the other members of the series, 19 and 21. This may be attributable to the diminished change in dipole moment, which is associated with that vibrational mode due to the lower electronegativity of sulfur compared to oxygen and nitrogen. The spectrum of 23 also shows moderately strong absorbances at $527 \mathrm{~cm}^{-1}$ for the coupled motions of the carbons in the ring, and $373 \mathrm{~cm}^{-1}$ for the in-plane vibrations of the $\mathrm{S}-\mathrm{C} \equiv \mathrm{C}$ group. 

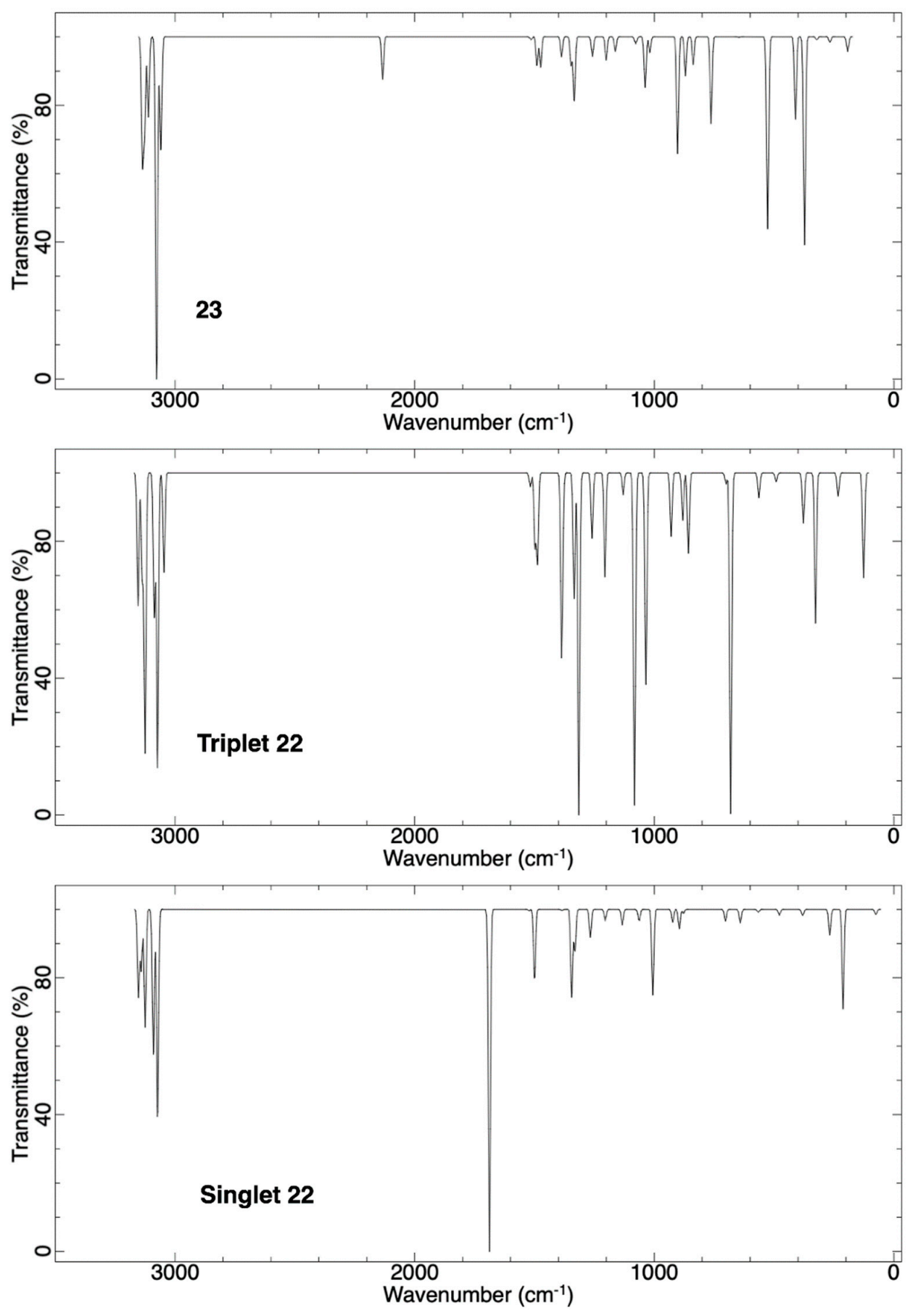

Figure 13. Vibrational spectra computed at CCSD/6-311+ $\mathrm{G}^{* *}$ for singlet 22 (bottom), triplet 22 (middle), and 23 (top).

\subsection{Alkylidenecarbenes Derived from $\delta$-Lactam, $\delta$-Lactone, and $\delta$-Thiolactone}

Members in this group are considerably less strained than their counterparts in the $\beta$ - and $\gamma$-series. CCSD(T)/cc-pVTZ//B3LYP/6-311+G** and CCSD(T)/cc-pVTZ//CCSD/6-311+G* calculations reveal that the $\Delta \mathrm{E}_{\mathrm{S} \text {-T }}$ gaps of the alkylidenecarbenes in the $\delta$-series are much larger than seen for analogously substituted species in the previous two series, and favor the singlet. The cycloalkynes in this series are also substantially more stable than their corresponding alkylidencarbene isomers. Structures and energies of these carbenes as well the PES for conversion of singlet carbenes into the corresponding 1-X-cyclohept-2-ynes, by a 1,2-shift of X or carbon (Scheme 6), are described below. 


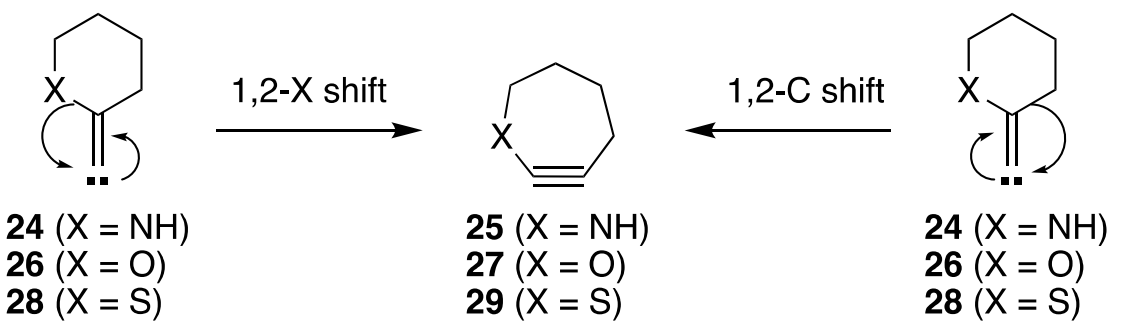

Scheme 6. Ring expansion of singlet alkylidenecarbenes, derived from $\delta$-lactam, $\delta$-lactone, and $\delta$-thiolactone, by a 1,2 shift of either $\mathrm{X}$ or carbon.

\subsubsection{Ring Expansion of 2-(1-Azacyclohexylidene)carbene (24) into 1-Azacyclohept-2-yne (25)}

As seen in Figure 14, CCSD(T)/cc-pVTZ//CCSD/6-311+G** calculations show that singlet 24 lies $24.6 \mathrm{kcal} / \mathrm{mol}$ below the triplet and $19.7 \mathrm{kcal} / \mathrm{mol}$ above the azacycloheptyne 25 . Structurally, the ring in singlet 24 adopts the familiar chair conformation but in the triplet, the portion of the ring in the vicinity of the double bond is essentially planar. Another interesting feature in singlet $\mathbf{2 4}$ is that the double bond appears to sharply bend toward the nitrogen with the $\mathrm{N}-\mathrm{C}=\mathrm{C}$ angle compressing to $78.5^{\circ}$ and the $\mathrm{C}-\mathrm{C}=\mathrm{C}$ angle increasing to $154.5^{\circ}$. This could be rationalized as a stabilizing interaction between the lone pair on nitrogen and the empty p orbital on the carbenic carbon. Somewhat counterintuitively, despite this structural distortion, the formation of 25 by a 1,2-nitrogen shift still has a rather large barrier of $24.4 \mathrm{kcal} / \mathrm{mol}$ compared to a much smaller activation energy of $10.8 \mathrm{kcal} / \mathrm{mol}$ required for the 1,2-carbon shift. Results obtained with CCSD(T)/cc-pVTZ/ / B3LYP/6-311+G** calculations are provided in the Supplementary Materials (Figure S7).

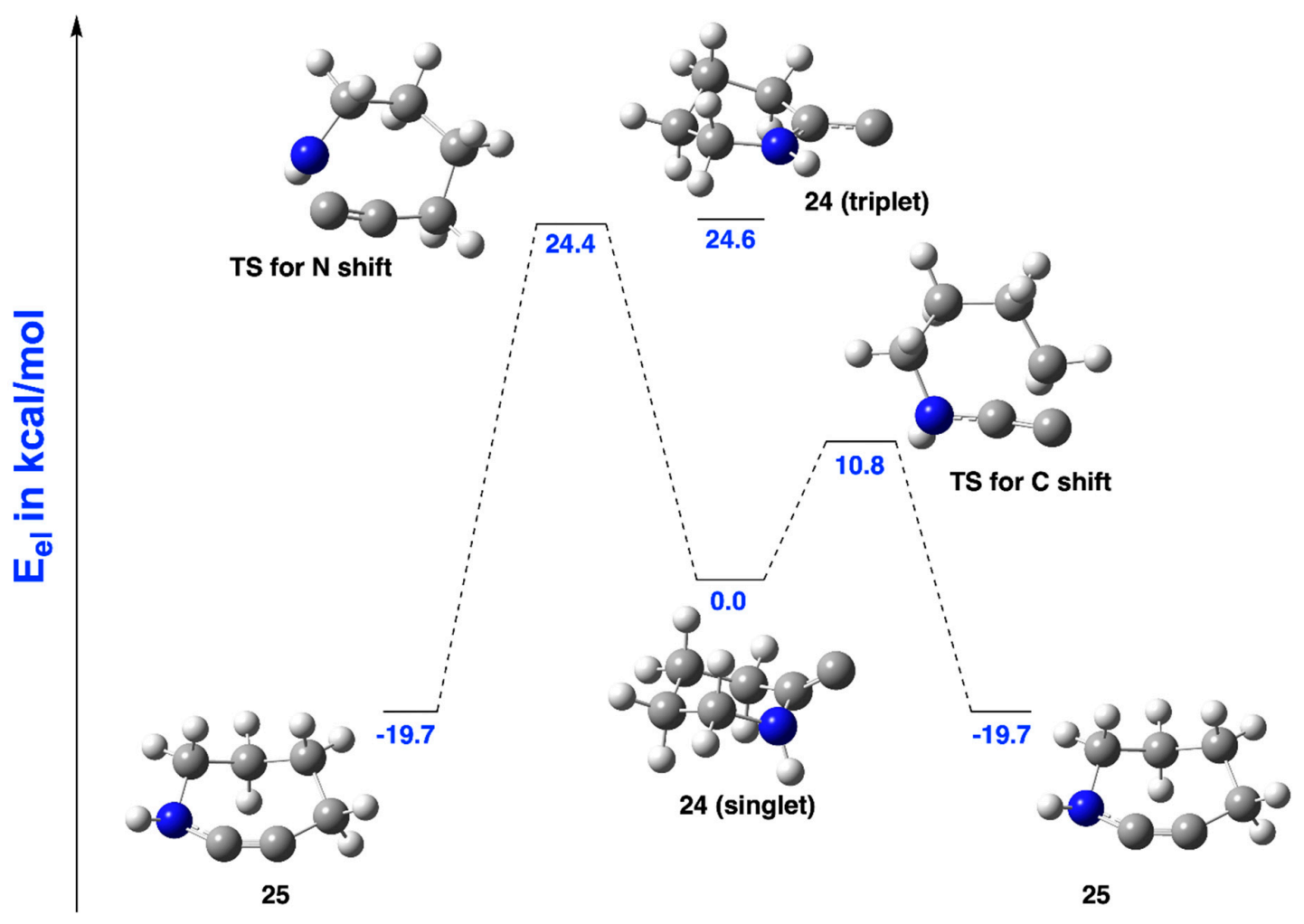

Figure 14. $\mathrm{CCSD}(\mathrm{T}) / \mathrm{cc}-\mathrm{pVTZ} / / \mathrm{CCSD} / 6-311+\mathrm{G}^{* *}$ structures and energies of singlet and triplet 24, and the PES for the conversion of singlet 24 into 1-azacyclohept-2-yne (25) by two different pathways.

The vibrational spectra of $\mathbf{2 4}$ and $\mathbf{2 5}$ computed at CCSD/6-311+G** are shown in Figure 15. Singlet 24 has a strong band at $786 \mathrm{~cm}^{-1}$ caused by the out-of-plane wagging motion of the $\mathrm{N}-\mathrm{H}$ bond. The 
spectrum of triplet 24 shows a strong band at $1589 \mathrm{~cm}^{-1}$ that corresponds to the in-plane vibrations of the $C=C-N$ moiety, and another band at $1409 \mathrm{~cm}^{-1}$ that is associated with the coupled motions of atoms in the ring. The characteristic $\mathrm{C} \equiv \mathrm{C}$ stretching frequency in $\mathbf{2 5}$ appears as a moderately strong band at $2264 \mathrm{~cm}^{-1}$. Cycloalkyne 25 also shows a strong absorbance at $767 \mathrm{~cm}^{-1}$ and a weaker band at $750 \mathrm{~cm}^{-1}$, both of which are associated with the out-of-plane bending motions of the N-H bond.
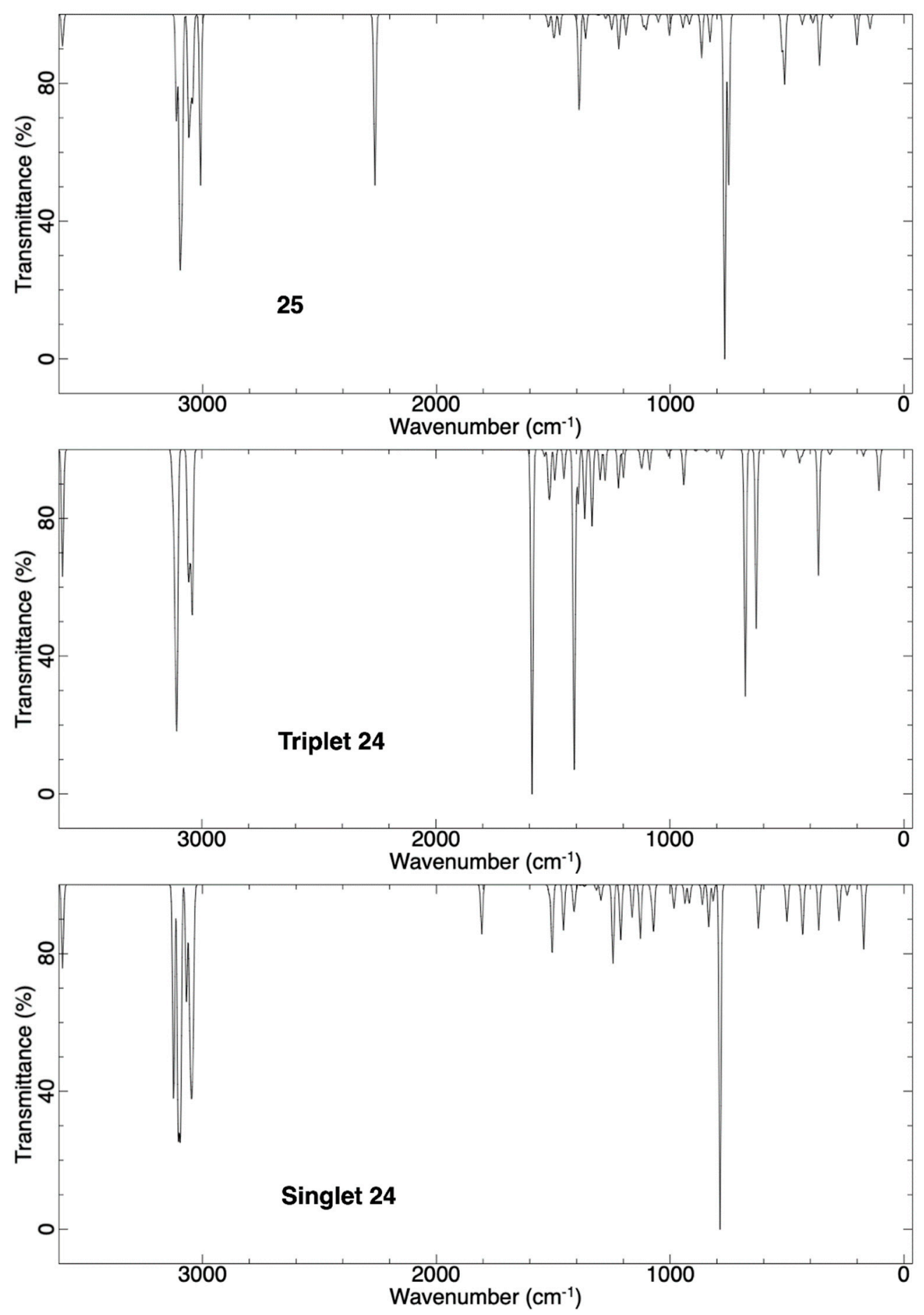

Figure 15. Vibrational spectra computed at CCSD/6-311+G* for singlet 24 (bottom), triplet 24 (middle), and 25 (top). 
2.3.2. Ring Expansion of 2-(1-Oxacyclohexylidene)carbene (26) into 1-Oxacyclohept-2-yne (27)

$\operatorname{CCSD}(\mathrm{T}) / \mathrm{cc}-\mathrm{pVTZ} / / \mathrm{CCSD} / 6-311+\mathrm{G}^{* *}$ structures and energies of $\mathbf{2 6}$ (singlet and triplet), and the PES for the rearrangement of singlet 26 into 27, are represented in Figure 16. These calculations show that singlet $\mathbf{2 6}$ is lower in energy than the triplet by $29.9 \mathrm{kcal} / \mathrm{mol}$. Similar to what was observed with 24 above, the six-membered ring in singlet $\mathbf{2 6}$ adopts a chair conformation whereas the triplet features a somewhat flattened portion of the ring near the double bond. Unlike singlet 24, however, there is no inclination for the double bond in singlet 26 to 'lean' toward the oxygen. The cyclohexyne 27 is $22 \mathrm{kcal} / \mathrm{mol}$ below singlet $\mathbf{2 6}$. The transition state for the 1,2-carbon shift to rearrange from singlet 25 into 26 lies $8.1 \mathrm{kcal} / \mathrm{mol}$ above the carbene, whereas the barrier to form 27 by a 1,2-oxygen shift is much higher at $26.1 \mathrm{kcal} / \mathrm{mol}$. Structures and energies for this system calculated at CCSD(T)/cc-pVTZ/ / B3LYP/6-311+G* are provided in the Supplementary Materials (Figure S8).

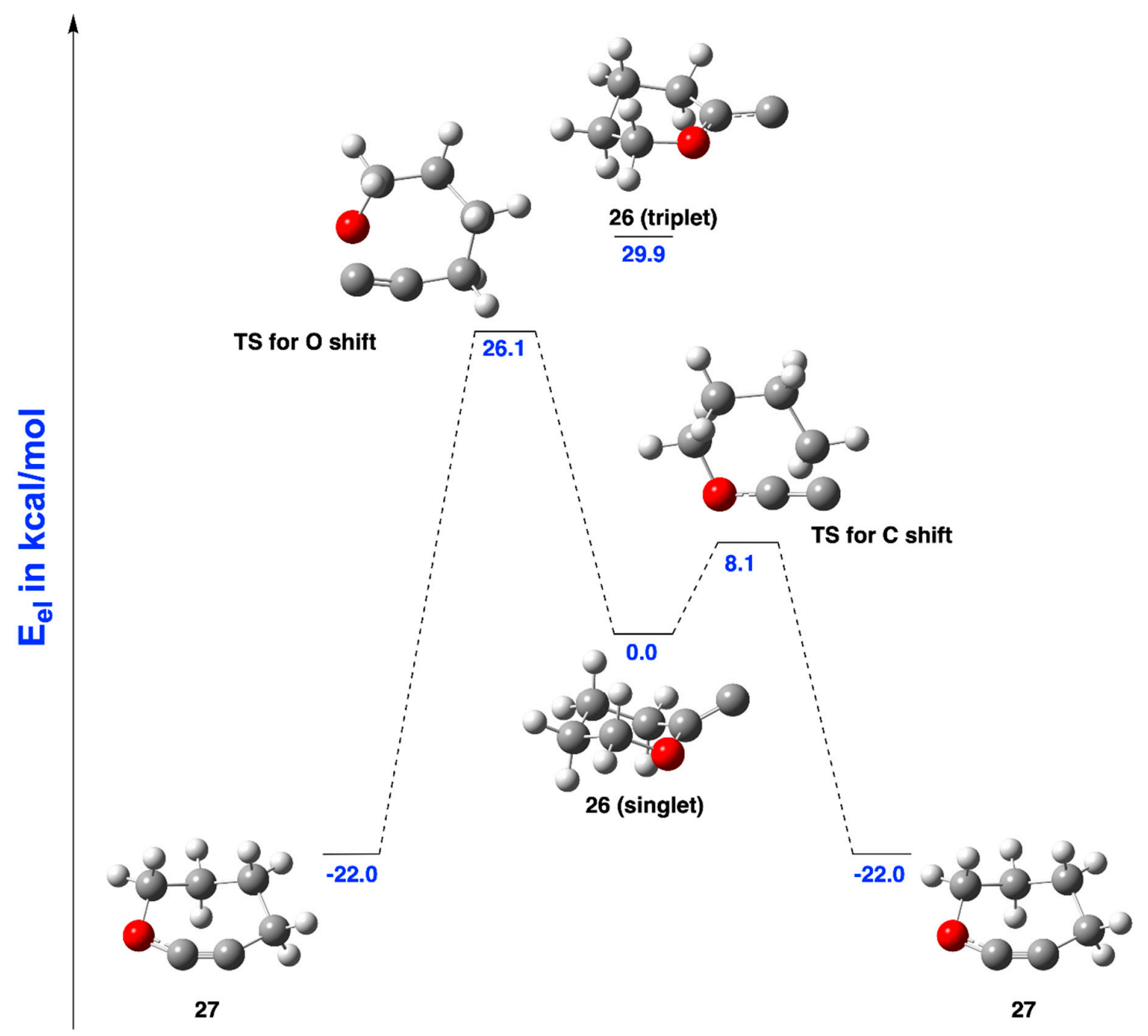

Figure 16. $\mathrm{CCSD}(\mathrm{T}) / \mathrm{cc}-\mathrm{pVTZ} / / \mathrm{CCSD} / 6-311+\mathrm{G}^{* *}$ structures and energies of singlet and triplet 26, and the PES for the conversion of singlet 26 into 1-oxacyclohept-2-yne (27) by two different pathways.

Vibrational spectra of $\mathbf{2 6}$ and $\mathbf{2 7}$ computed at CCSD/6-311+G** are shown in Figure 17. Singlet 26 shows a strong band at $1190 \mathrm{~cm}^{-1}$ for the stretching vibrations of the bond connecting oxygen with the endocyclic sp ${ }^{2}$ carbon. Triplet 26 displays bands at $1325 \mathrm{~cm}^{-1}$ for the wagging motions of the methylene groups and $1270 \mathrm{~cm}^{-1}$ for vibrations associated with the $\mathrm{O}-\mathrm{C}=\mathrm{C}$ group. The most distinctive absorbance in the spectrum of cyclohexyne 27 is a strong band at $2276 \mathrm{~cm}^{-1}$ corresponding to the alkynyl stretch. 

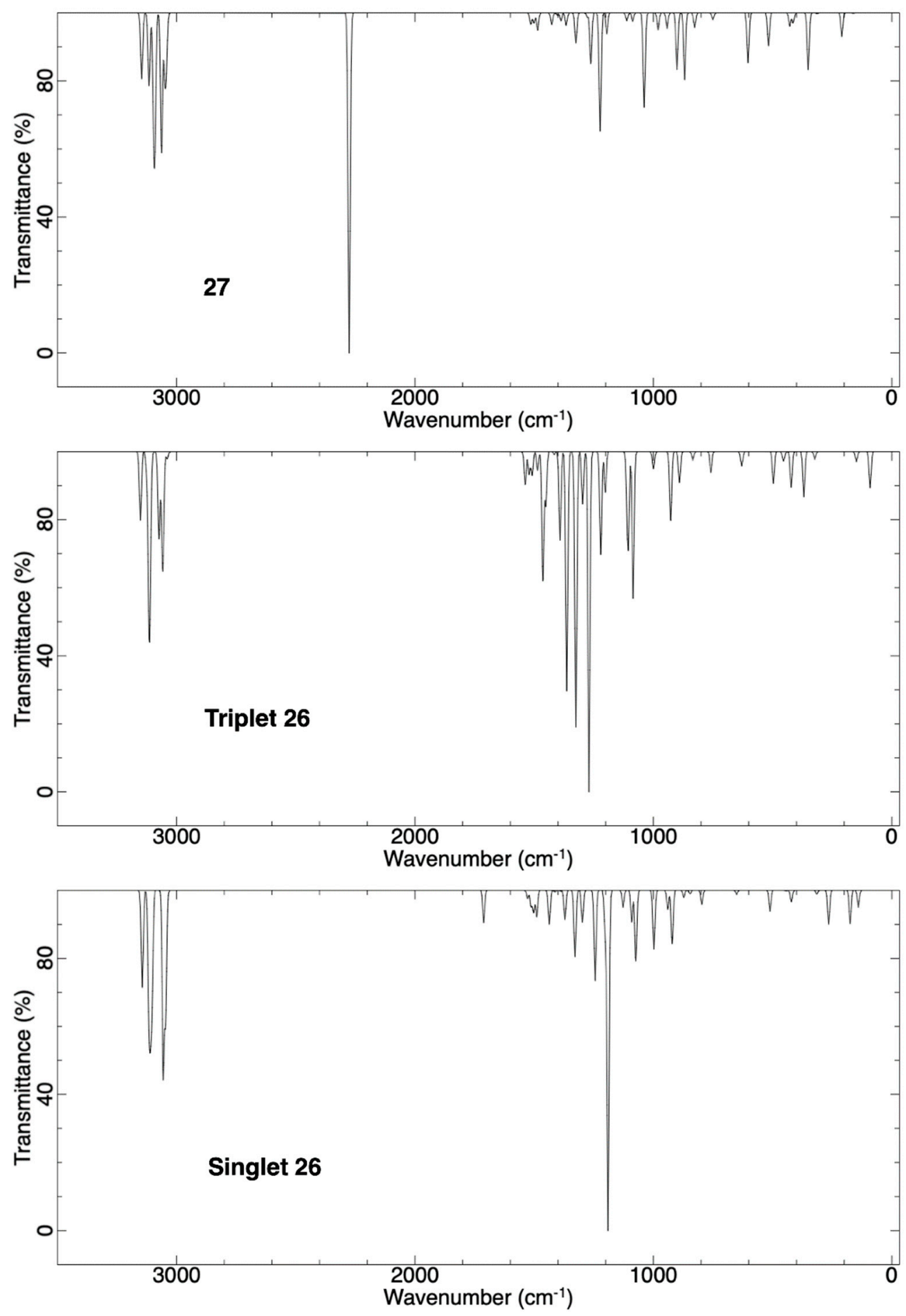

Figure 17. Vibrational spectra computed at CCSD $/ 6-311+\mathrm{G}^{* *}$ for singlet $\mathbf{2 6}$ (bottom), triplet $\mathbf{2 6}$ (middle), and 27 (top).

2.3.3. Ring Expansion of 2-(1-Thiocyclohexylidene)carbene (28) into 1-Thiocyclohept-2-yne (29)

CCSD(T)/cc-pVTZ/ /CCSD/6-311+G $\mathrm{G}^{* *}$ calculations show that singlet 28 is $46.1 \mathrm{kcal} / \mathrm{mol}$ lower in energy than the triplet, and this $\Delta \mathrm{E}_{\mathrm{S}-\mathrm{T}}$ gap is the largest observed for all carbene species in this study (Figure 18). Singlet 28 also shows a chair conformation in the six-membered ring while the triplet has a significantly planarized ring around the double bond. The structure of singlet $\mathbf{2 8}$ closely resembles that of the aza analog 24 in that the carbenic center is tilted toward the sulfur. This leads to an unusually 
small S- $\mathrm{C}=\mathrm{C}$ bond angle of $83.1^{\circ}$ whereas the $\mathrm{C}-\mathrm{C}=\mathrm{C}$ angle widens to $150.8^{\circ}$. As also shown in Figure 18 , cycloheptyne 29 lies $17.2 \mathrm{kcal} / \mathrm{mol}$ below singlet 28 . Consistent with the behavior of the other two sulfur-containing singlet carbenes discussed above (16 and 22), the 1,2-sulfur shift in singlet $\mathbf{2 8}$ to form 29 has a lower barrier of $9.02 \mathrm{kcal} / \mathrm{mol}$ relative to a 1,2-carbon shift, which needs to surmount a barrier of $21.8 \mathrm{kcal} / \mathrm{mol}$. Results of calculations on this system at the CCSD(T)/cc-pVTZ/ / B3LYP/6-311+G** level of theory are reported in the Supplementary Materials (Figure S9).

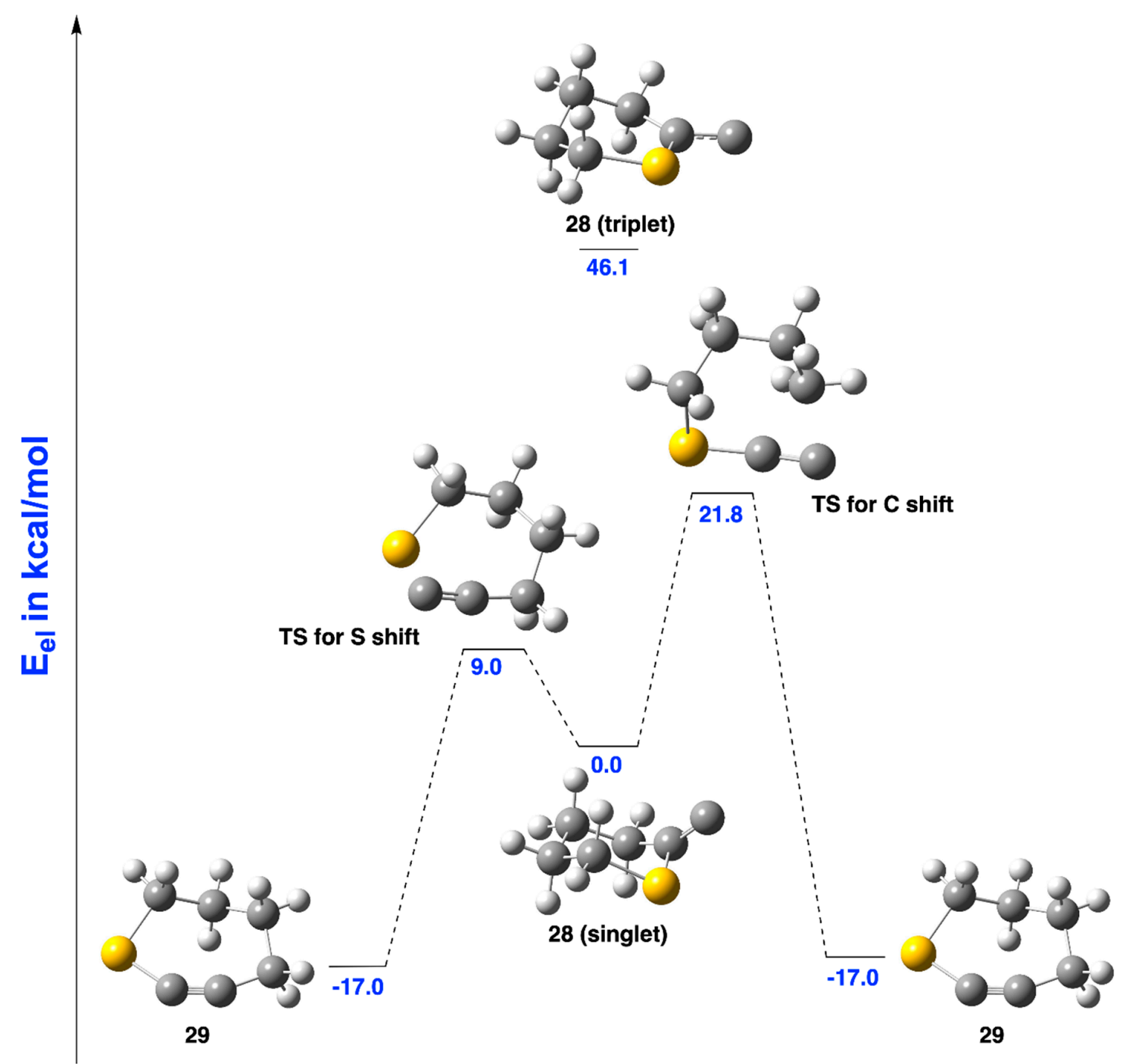

Figure 18. $\operatorname{CCSD}(\mathrm{T}) / \mathrm{cc}-\mathrm{pVTZ} / / \mathrm{CCSD} / 6-311+\mathrm{G}^{* *}$ structures and energies of singlet and triplet 28, and the PES for the conversion of singlet 28 into 1-thiocyclohept-2-yne (29) by two different pathways.

Vibrational spectra of $\mathbf{2 8}$ and 29, computed at CCSD/6-311+G**, are shown in Figure 19. The spectrum of singlet 28 shows a prominent band for the $C=C$ stretch at $1798 \mathrm{~cm}^{-1}$ and another weak absorbance at $630 \mathrm{~cm}^{-1}$ for the stretching of the bond between sulfur and the endocyclic sp $\mathrm{sarbon}^{2}$. Triplet 28 shows bands at $1330 \mathrm{~cm}^{-1}$ and $1284 \mathrm{~cm}^{-1}$ that correspond to the $\mathrm{C}=\mathrm{C}$ stretch coupled to motions of the ring carbons. The $C \equiv C$ stretch in 29 shows a weak band at $2222 \mathrm{~cm}^{-1}$, and the absorbance for the stretching vibrations of the bond connecting sulfur and the alkynyl group appears at $692 \mathrm{~cm}^{-1}$. 

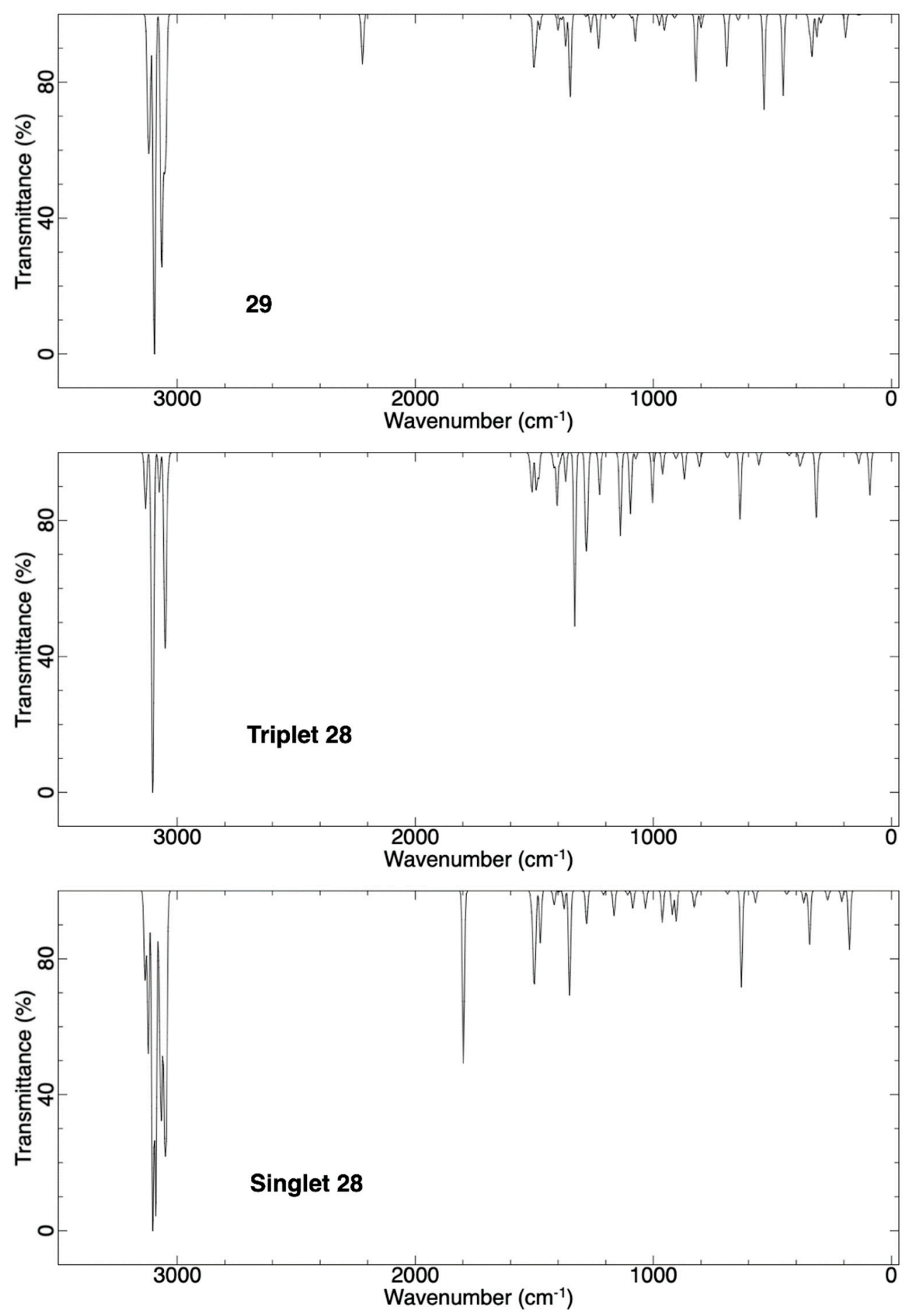

Figure 19. Vibrational spectra computed at CCSD $/ 6-311+\mathrm{G}^{* *}$ for singlet 28 (bottom), triplet 28 (middle), and 29 (top).

\section{Computational Methods}

All calculations were carried out with Gaussian 09 [55] and Gaussian 16 [56], using methods and basis sets described in the text. Graphics of structures used in the potential energy diagrams were generated with GaussView6 [57]. The vibrational spectra were produced using Avogadro [58]. Restricted methods were used for singlet species and unrestricted for triplet. The spin expectation values, $\left\langle\mathrm{S}^{2}\right\rangle$, were found to be 2.000 for all the triplet carbenes. The stationary points obtained from 
geometry optimizations were verified as minima (zero imaginary frequency) or transition states (one imaginary frequency) by subsequent frequency calculations. Intrinsic reaction coordinate calculations were also performed on all transition states found at the B3LYP/6-311+G* level of theory to ensure that they connected the correct minima.

The CCSD/6-311+G** and CCSD/cc-pVTZ/ /CCSD/6-311+G** T1 diagnostic [59] was computed for all structures, and the values were generally less than 0.02 , as recommended. However, for a few cases, specifically in the beta series, the T1 value was in the range of 0.02-0.05: not alarmingly high, but slightly above the ideal range. In order to confirm that the computed energies were still reliable, we carried out additional single-point calculations for the beta series. We chose for this purpose the Brueckner doubles method, with quadruples and triples: BD(TQ) [60-62]. It has the advantage of representing a slightly different approach to configuration interaction than coupled cluster, and especially with quadruple as well as triple excitations included, should provide even more reliable energies [63]. Since BD(TQ)/cc-pVTZ would be quite demanding computationally, we instead performed $\mathrm{BD}(\mathrm{TQ}) / \mathrm{cc}-\mathrm{pVDZ}$ and $\mathrm{BD}(\mathrm{T}) / \mathrm{cc}-\mathrm{pVTZ}$ calculations, and estimated the BD(TQ)/cc-pVTZ energy as BD(TQ)/cc-pVDZ + BD(T)/cc-pVTZ - BD(T)/cc-pVDZ. The energy differences computed using this procedure differed from those obtained using CCSD/cc-pVTZ/ /CCSD/6-311+G** by -0.1 to $+0.7 \mathrm{kcal} / \mathrm{mol}$, i.e., they were generally $0.3-0.5 \mathrm{kcal} / \mathrm{mol}$ higher, but never more than 0.7 higher (or more than $0.1 \mathrm{kcal} / \mathrm{mol}$ lower). The similarity of results using a significantly different correlation procedure lends confidence to the energies reported above, despite the somewhat higher than ideal $\mathrm{T} 1$ values for a limited number of cases. A spreadsheet summarizing the computational results is provided in the Supplementary Materials.

\section{Conclusions}

A series of cyclic alkylidenecarbenes, formally obtained by replacing the carbonyl oxygen of four-, five-, and six-membered lactams, lactones, and thiolactones with a divalent carbon, were modeled at the CCSD(T)/cc-pVTZ/ / B3LYP/6-311+G** and CCSD(T)/cc-pVTZ//CCSD/6-311+G** levels of theory. In all cases, the singlet carbenes were found to be considerably more stable than the triplets. The $\Delta \mathrm{E}_{\mathrm{S} \text { - } \mathrm{T}}$ gap increased with increasing ring size for each type of heteroatom substituent. Structures and energies of the cycloalkynes formed by ring expansion of the singlet carbenes were modeled using both levels of theory described above, although 1-oxacyclopent-2-yne (15) was found to be a minimum by CCSD/6-311+G** calculations but not at the B3LYP/6-311+G* level. The structures of 1-azacyclopent-2-yne (13) and 15 displayed elongated lengths for the alkynl bonds. Furthermore, 2-(1-azacyclobutylidene)carbene (12) was found to be nearly isoenergetic with its ring-expanded isomer 13, and 15 was notably higher in energy than 2-(1-oxacyclobutylidene)carbene (14). In all other cases, the cycloalkynes were lower in energy than the corresponding carbenes.

As ring expansion of the title alkylidenenecarbenes in this study could occur by a 1,2-shift of either the heteroatom or carbon, both pathways were modeled. For the nitrogen- and oxygen-substituted systems, the barrier for 1,2-carbon shifts were always lower in energy than those for the corresponding 1,2-nitrogen or oxygen shifts. In the case of sulfur-substituted carbenes, however, sulfur migration was significantly more facile than the carbon shift. These predictions, summarized in Figure 20, offer a platform for experimental verification using carbenes bearing appropriate isotopic labels.

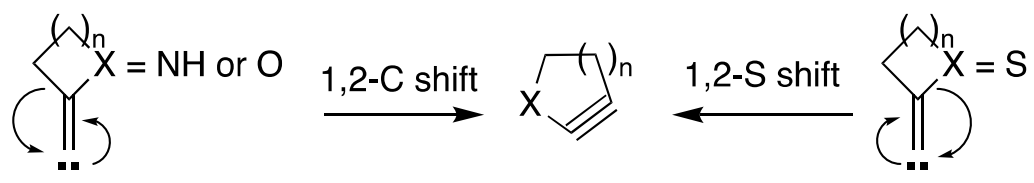

$$
\mathrm{n}=1,2 \text {, or } 3
$$

Figure 20. Summary of results depicting preferred rearrangement modes for the alkylidenecarbenes discussed in this study. 
This work bears a striking parallel to the experimental observations of Robson and Shechter who investigated the migratory aptitudes in carbenes of the type $\mathbf{3 0}$ (Figure 21) generated from the corresponding diazo compounds [64]. They noted that neither nitrogen nor oxygen substituents migrated to the carbenic center in 30 but the sulfur group did undergo a 1,2-shift.

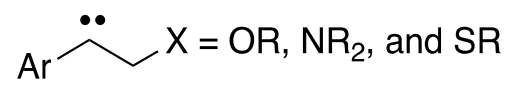

30

Figure 21. Carbenes studied by Robson and Shechter [64] to probe migratory aptitudes of substituents at the $\beta$-position.

As alluded to above, one explanation for the "nonmigration" of nitrogen and oxygen may be due to their ability to stabilize the transition state for 1,2-carbon shift. Results of NPA calculations [53,54] (see Supplementary Materials) reveal that in all of the title carbenes in this study (with the sole exception of the sulfur-containing 28), there is a depletion of electron density at the migration origin and an accumulation of negative charge at the migration terminus, during the carbon shift. Perhaps the nitrogen and oxygen, both of which are effective $\pi$ donors, stabilize the developing positive charge at the adjacent carbon (migration origin). Another explanation is that the nitrogen- and oxygen-containing alkylidene carbenes reported in this study enjoy resonance stabilization as exemplified in Figure 2. Such resonance effects strengthen the $\mathrm{X}-\mathrm{C}_{\mathrm{sp} 2}$ bond making it harder to cleave. Furthermore, the lone pair on oxygen and nitrogen can remain in conjugation with the adjacent carbon-carbon $\pi$ bond even during the 1,2-carbon shift. Sulfur, on the other hand, is less effective at $\pi$ conjugation with carbon due to significant differences in the sizes and energies of the interacting $p$ orbitals in the two atoms (3p vs. $2 p)$. Furthermore, given the larger size and nucleophilicity of sulfur, it can interact with the empty orbital on the carbenic center to initiate bonding en route to a 1,2-shift.

Vibrational spectra were calculated for all carbenes (singlets and triplets), and their ring-expanded isomers. These spectra are of potential value in matrix isolation experiments aimed at generating these species. They allow comparison of experimentally determined vibrational frequencies with those that are computed to facilitate identification.

Supplementary Materials: The Supplementary Materials are available online.

Author Contributions: Conceptualization, D.M.T.; Methodology, D.M.T. and P.R.R.; Formal analysis, D.M.T., P.R.R., N.N.T.L., J.J., and J.M.P.; Investigation, D.M.T., P.R.R., N.N.T.L., J.J., and J.M.P.; Resources, D.M.T. and P.R.R.; Data curation, D.M.T. and P.R.R.; Writing-Original draft preparation, D.M.T. and P.R.R.; Writing-Review and editing, D.M.T., P.R.R., N.N.T.L., J.J., and J.M.P.; Supervision, D.M.T. and P.R.R.; Project administration, D.M.T.; Funding acquisition, D.M.T.

Funding: This research was funded by the National Science Foundation, grant number CHE-1665278.

Acknowledgments: D.M.T. gratefully acknowledges computational support and resources provided by Randall Downer, Lindsey Madison, and Stephanie Taylor at Colby College.

Conflicts of Interest: The authors declare no conflict of interest. The funders had no role in the design of the study; in the collection, analyses, or interpretation of data; in the writing of the manuscript, or in the decision to publish the results.

\section{References}

1. Fritsch, P. On the Preparation of Diphenylacetaldehyde and a New Synthesis of Tolene Derivatives. Justus Liebigs Ann. Chem. 1894, 279, 319-323. [CrossRef]

2. Buttenberg, W.P. Condensation of the Dichloroacetal with Phenol and Toluene. Justus Liebigs Ann. Chem. 1894, 279, 324-337. [CrossRef]

3. Wiechell, H. Condensation of Dichloroacetate with Anisole and Phenetol. Justus Liebigs Ann. Chem. 1894, 279, 337-344. [CrossRef] 
4. Knorr, R. Alkylidenecarbenes, Alkylidenecarbenoids, and Competing Species: Which Is Responsible for Vinylic Nucleophilic Substitution, [1 + 2] Cycloadditions, 1,5-CH Insertions, and the Fritsch-Buttenberg-Wiechell Rearrangement? Chem. Rev. 2004, 104, 3795-3849. [CrossRef] [PubMed]

5. Jahnke, E.; Tykwinski, R.R. The Fritsch-Buttenberg-Wiechell rearrangement: Modern applications for an old reaction. Chem. Commun. 2010, 46, 3235-3249.

6. Grainger, R.S.; Munro, K.R. Recent advances in alkylidene carbene chemistry. Tetrahedron 2015, 71, 7795-7835. [CrossRef]

7. Hopf, H.; Grunenberg, J. Angle-strained cycloalkynes. In Strained Hydrocarbons; Dodziuk, H., Ed.; Wiley-VCH: Weinheim, Germany, 2009; pp. 375-397.

8. Detert, H. Angle-strained heterocyclic alkynes with five to ten ring atoms. Targets Heterocycl. Syst. 2011, 15, 1-49.

9. Sahu, B.; Gururaja, G.N.; Kumar, T.; Chatterjee, A.; Ganguly, B.; Mobin, S.M.; Namboothiri, I.N.N. Generation and Trapping of a Cage Annulated Vinylidenecarbene and Approaches to Its Cycloalkyne Isomer. J. Org. Chem. 2012, 77, 6998-7004. [CrossRef]

10. Moore, K.A.; Vidaurri-Martinez, J.S.; Thamattoor, D.M. The Benzylidenecarbene-Phenylacetylene Rearrangement: An Experimental and Computational Study. J. Am. Chem. Soc. 2012, 134, 20037-20040. [CrossRef]

11. Hardikar, T.S.; Warren, M.A.; Thamattoor, D.M. Photochemistry of 1-(propan-2-ylidene)-1a,9b-dihydro1H-cyclopropa[1]phenanthrene. Tetrahedron Lett. 2015, 56, 6751-6753. [CrossRef]

12. Yang, X.; Languet, K.; Thamattoor, D.M. An Experimental and Computational Investigation of ( $\alpha$-Methylbenzylidene)carbene. J. Org. Chem. 2016, 81, 8194-8198. [CrossRef] [PubMed]

13. Du, L.; Lan, X.; Phillips, D.L.; Coldren, W.H.; Hadad, C.M.; Yang, X.; Thamattoor, D.M. Direct Observation of an Alkylidenecarbene by Ultrafast Transient Absorption Spectroscopy. J. Phys. Chem. A 2018. [CrossRef] [PubMed]

14. Maurer, D.P.; Fan, R.; Thamattoor, D.M. Photochemical Generation of Strained Cycloalkynes from Methylenecyclopropanes. Angew. Chem. Int. Ed. 2017, 56, 4499-4501. [CrossRef] [PubMed]

15. Fan, R.; Wen, Y.; Thamattoor, D.M. Photochemical generation and trapping of 3-oxacyclohexyne. Org. Biomol. Chem. 2017, 15, 8270-8275. [CrossRef] [PubMed]

16. Liebman, J.F.; Greenberg, A. A survey of strained organic molecules. Chem. Rev. 1976, 76, 311-365. [CrossRef]

17. Krebs, A.; Wilke, J. Angle strained cycloalkynes. Top. Curr. Chem. 1983, 109, 189-233.

18. Meier, H. Cyclic alkynes, enynes and dienynes. A synthetic challenge. Adv. Strain Organic Chem. 1991, 1, 215-272.

19. Debets, M.F.; van Berkel, S.S.; Dommerholt, J.; Dirks, A.J.; Rutjes, F.P.J.T.; van Delft, F.L. Bioconjugation with Strained Alkenes and Alkynes. Acc. Chem. Res. 2011, 44, 805-815. [CrossRef] [PubMed]

20. Gampe, C.M.; Carreira, E.M. Arynes and Cyclohexyne in Natural Product Synthesis. Angew. Chem. Int. Ed. 2012, 51, 3766-3778. [CrossRef] [PubMed]

21. Medina, J.M.; McMahon, T.C.; Jimenez-Oses, G.; Houk, K.N.; Garg, N.K. Cycloadditions of cyclohexynes and cyclopentyne. J. Am. Chem. Soc. 2014, 136, 14706-14709. [CrossRef] [PubMed]

22. Tlais, S.F.; Danheiser, R.L. N-Tosyl-3-Azacyclohexyne. Synthesis and Chemistry of a Strained Cyclic Ynamide. J. Am. Chem. Soc. 2014, 136, 15489-15492. [CrossRef] [PubMed]

23. Shah, T.K.; Medina, J.M.; Garg, N.K. Expanding the Strained Alkyne Toolbox: Generation and Utility of Oxygen-Containing Strained Alkynes. J. Am. Chem. Soc. 2016, 138, 4948-4954. [CrossRef] [PubMed]

24. Yoshida, S. Controlled reactive intermediates enabling facile molecular conjugation. Bull. Chem. Soc. Jpn. 2018, 91, 1293-1318. [CrossRef]

25. Qiu, D.; Shi, J.; Guo, Q.; Xu, Q.; Li, B.; Li, Y. Cyclohexenynone Precursors: Preparation via Oxidative Dearomatization Strategy and Reactivity. J. Am. Chem. Soc. 2018, 140, 13214-13218. [CrossRef] [PubMed]

26. Picazo, E.; Anthony, S.M.; Giroud, M.; Simon, A.; Miller, M.A.; Houk, K.N.; Garg, N.K. Arynes and Cyclic Alkynes as Synthetic Building Blocks for Stereodefined Quaternary Centers. J. Am. Chem. Soc. 2018, 140, 7605-7610. [CrossRef] [PubMed]

27. Agard, N.J.; Prescher, J.A.; Bertozzi, C.R. A Strain-Promoted [3 + 2] Azide-Alkyne Cycloaddition for Covalent Modification of Biomolecules in Living Systems. J. Am. Chem. Soc. 2004, 126, 15046-15047. [CrossRef] [PubMed] 
28. Sletten, E.M.; Bertozzi, C.R. Bioorthogonal Chemistry: Fishing for Selectivity in a Sea of Functionality. Angew. Chem. Int. Ed. 2009, 48, 6974-6998. [CrossRef]

29. Jewett, J.C.; Sletten, E.M.; Bertozzi, C.R. Rapid Cu-Free Click Chemistry with Readily Synthesized Biarylazacyclooctynones. J. Am. Chem. Soc. 2010, 132, 3688-3690. [CrossRef]

30. De Almeida, G.; Sletten, E.M.; Nakamura, H.; Palaniappan, K.K.; Bertozzi, C.R. Thiacycloalkynes for Copper-Free Click Chemistry. Angew. Chem. Int. Ed. 2012, 51, 2443-2447. [CrossRef]

31. McNitt, C.D.; Popik, V.V. Photochemical generation of oxa-dibenzocyclooctyne (ODIBO) for metal-free click ligations. Org. Biomol. Chem. 2012, 10, 8200-8202. [CrossRef]

32. Gold, B.; Dudley, G.B.; Alabugin, I.V. Moderating Strain without Sacrificing Reactivity: Design of Fast and Tunable Noncatalyzed Alkyne-Azide Cycloadditions via Stereoelectronically Controlled Transition State Stabilization. J. Am. Chem. Soc. 2013, 135, 1558-1569. [CrossRef] [PubMed]

33. Gold, B.; Batsomboon, P.; Dudley, G.B.; Alabugin, I.V. Alkynyl Crown Ethers as a Scaffold for Hyperconjugative Assistance in Noncatalyzed Azide-Alkyne Click Reactions: Ion Sensing through Enhanced Transition-State Stabilization. J. Org. Chem. 2014, 79, 6221-6232. [CrossRef] [PubMed]

34. Hagendorn, T.; Bräse, S. A new route to dithia- and thiaoxacyclooctynes via Nicholas reaction. RSC Adv. 2014, 4, 15493-15495. [CrossRef]

35. Debets, M.F.; Prins, J.S.; Merkx, D.; van Berkel, S.S.; van Delft, F.L.; van Hest, J.C.M.; Rutjes, F.P.J.T. Synthesis of DIBAC analogues with excellent SPAAC rate constants. Org. Biomol. Chem. 2014, 12, 5031-5037. [CrossRef] [PubMed]

36. Ni, R.; Mitsuda, N.; Kashiwagi, T.; Igawa, K.; Tomooka, K. Heteroatom-embedded Medium-Sized Cycloalkynes: Concise Synthesis, Structural Analysis, and Reactions. Angew. Chem. Int. Ed. 2015, 54, 1190-1194. [CrossRef] [PubMed]

37. Harris, T.; Gomes, G.D.P.; Ayad, S.; Clark, R.J.; Lobodin, V.V.; Tuscan, M.; Hanson, K.; Alabugin, I.V. Twisted Cycloalkynes and Remote Activation of "Click" Reactivity. Chemisty 2017, 3, 629-640. [CrossRef]

38. Del Grosso, A.; Galanopoulos, L.D.; Chiu, C.K.C.; Clarkson, G.J.; O' Connor, P.B.; Wills, M. Strained alkynes derived from 2,2'-dihydroxy-1,1'-biaryls; synthesis and copper-free cycloaddition with azides. Org. Biomol. Chem. 2017, 15, 4517-4521. [CrossRef] [PubMed]

39. Nainar, S.; Kubota, M.; McNitt, C.; Tran, C.; Popik, V.V.; Spitale, R.C. Temporal Labeling of Nascent RNA Using Photoclick Chemistry in Live Cells. J. Am. Chem. Soc. 2017, 139, 8090-8093. [CrossRef]

40. Lyapunova, A.G.; Danilkina, N.A.; Rumyantsev, A.M.; Khlebnikov, A.F.; Chislov, M.V.; Starova, G.L.; Sambuk, E.V.; Govdi, A.I.; Bräse, S.; Balova, I.A. Relative Reactivity of Benzothiophene-Fused Enediynes in the Bergman Cyclization. J. Org. Chem. 2018, 83, 2788-2801. [CrossRef] [PubMed]

41. Lyapunova, A.G.; Danilkina, N.A.; Khlebnikov, A.F.; Köberle, B.; Bräse, S.; Balova, I.A. Oxaenediynes through the Nicholas-Type Macrocyclization Approach. Eur. J. Org. Chem. 2016, 2016, 4842-4851. [CrossRef]

42. Becke, A.D. Density-functional exchange-energy approximation with correct asymptotic behavior. Phys. Rev. A Gen. Phys. 1988, 38, 3098-3100. [CrossRef]

43. Lee, C.; Yang, W.; Parr, R.G. Development of the Colle-Salvetti Correlation-Energy Formula into a Functional of the Electron Density. Phys. Rev. B 1988, 37, 785-789. [CrossRef]

44. Becke, A.D. Density-Functional Thermochemistry. III. The Role of Exact Exchange. J. Chem. Phys. 1993, 98, 5648-5652. [CrossRef]

45. Bartlett, R.J.; Purvis, G.D., III. Many-body perturbation theory, coupled-pair many-electron theory, and the importance of quadrupole excitations for the correlation problem. Int. J. Quantum Chem. 1978, 14, 561-581. [CrossRef]

46. Purvis, G.D., III; Bartlett, R.J. A full coupled-cluster singles and doubles model: The inclusion of disconnected triples. J. Chem. Phys. 1982, 76, 1910-1918. [CrossRef]

47. Scuseria, G.E.; Janssen, C.L.; Schaefer, H.F., III. An efficient reformulation of the closed-shell coupled cluster single and double excitation (CCSD) equations. J. Chem. Phys. 1988, 89, 7382-7387. [CrossRef]

48. Jacox, M.E. The spectroscopy of molecular reaction intermediates trapped in the solid rare gases. Chem. Soc. Rev. 2002, 31, 108-115. [CrossRef] [PubMed]

49. Andrews, L. IR and Raman Spectroscopies, Matrix Isolation Studies. In Encyclopedia of Spectroscopy and Spectrometry, 3rd ed.; Lindon, J.C., Tranter, G.E., Koppenaal, D.W., Eds.; Academic Press: Oxford, UK, 2017; pp. 359-364. 
50. Bally, T. Matrix isolation. In Research on Chemical Intermediates; Moss, R.A., Platz, M.S., Jones, M., Jr., Eds.; John Wiley \& Sons: Hoboken, NJ, USA, 2004; pp. 797-845.

51. Allen, F.; Watson, D.; Brammer, L.; Orpen, A.; Taylor, R. Typical interatomic distances: Organic compounds. In International Tables for Crystallography; Prince, E., Ed.; Springer: Dordrecht, The Netherlands, 2006; pp. 790-811.

52. Nickon, A. New perspectives on carbene rearrangements: Migratory aptitudes, bystander assistance, and geminal efficiency. Acc. Chem. Res. 1993, 26, 84-89. [CrossRef]

53. Reed, A.E.; Weinstock, R.B.; Weinhold, F. Natural population analysis. J. Chem. Phys. 1985, 83, 735-746. [CrossRef]

54. Reed, A.E.; Curtiss, L.A.; Weinhold, F. Intermolecular interactions from a natural bond orbital, donor-acceptor viewpoint. Chem. Rev. 1988, 88, 899-926. [CrossRef]

55. Frisch, M.J.; Trucks, G.W.; Schlegel, H.B.; Scuseria, G.E.; Robb, M.A.; Cheeseman, J.R.; Scalmani, G.; Barone, V.; Petersson, G.A.; Nakatsuji, H.; et al. Gaussian 09, Revision D.01; Gaussian, Inc.: Wallingford, CT, USA, 2016.

56. Frisch, M.J.; Trucks, G.W.; Schlegel, H.B.; Scuseria, G.E.; Robb, M.A.; Cheeseman, J.R.; Scalmani, G.; Barone, V.; Petersson, G.A.; Nakatsuji, H.; et al. Gaussian 16, Revision A.03; Gaussian, Inc.: Wallingford, CT, USA, 2016.

57. Dennington, R.; Keith, T.A.; Millam, J.M. GaussView, Version 6; Semichem Inc.: Shawnee Mission, KS, USA, 2016.

58. Avogadro: An Open-Source Molecular Builder and Visualization Tool. Available online: http://avogadro.cc/ (accessed on 6 February 2019).

59. Lee, T.J.; Taylor, P.R. A diagnostic for determining the quality of single-reference electron correlation methods. Int. J. Quantum Chem. 1989, 36, 199-207. [CrossRef]

60. Dykstra, C.E. An examination of the Brueckner condition for the selection of molecular orbitals in correlated wavefunctions. Chem. Phys. Lett. 1977, 45, 466-469. [CrossRef]

61. Handy, N.C.; Pople, J.A.; Head-Gordon, M.; Raghavachari, K.; Trucks, G.W. Size-consistent Brueckner theory limited to double substitutions. Chem. Phys. Lett. 1989, 164, 185-192. [CrossRef]

62. Raghavachari, K.; Pople, J.A.; Replogle, E.S.; Head-Gordon, M. Fifth order Moeller-Plesset perturbation theory: Comparison of existing correlation methods and implementation of new methods correct to fifth order. J. Phys. Chem. 1990, 94, 5579-5586. [CrossRef]

63. Lee, T.J.; Kobayashi, R.; Handy, N.C.; Amos, R.D. Comparison of the Brueckner and coupled-cluster approaches to electron correlation. J. Chem. Phys. 1992, 96, 8931-8937. [CrossRef]

64. Robson, J.H.; Shechter, H. Effects of neighboring heteroatoms in rearrangement to divalent carbon. J. Am. Chem. Soc. 1967, 89, 7112-7114. [CrossRef] 